\title{
Real-time and in-situ assessment of conduit permeability through diverse long-period tremors beneath Aso volcano, Japan
}

\author{
Jieming Niu*, Teh-Ru Alex Song \\ Seismological Laboratory, Department of Earth Sciences, University College London, WC1E 6BT London, United Kingdom
}

\section{A R T I C L E I N F O}

\section{Article history:}

Received 9 April 2020

Received in revised form 21 May 2020

Accepted 31 May 2020

Available online 16 June 2020

\section{Keywords:}

Aso volcano

Diverse long-period tremor

Matched filter

Conduit permeability

Conduit rheology

\begin{abstract}
A B S T R A C T
Long-period signal (LPs, 0.2-2 s) and very long-period signal (VLP, 2-100 s) observed in the shallow volcanic plumbing system are typically repetitive and time-invariant in their location and source mechanism, offering in-situ probes of hot fluid transport over the eruption cycles. While the amplitude and activity of volcanictectonic earthquakes and LP events have been commonly used to infer overpressure within their source region, one missing link is an observable that may permit inference on the change in the permeability of the conduit plug/wall, which can regulate the degree of pressurization, affect the mechanical strength of the surrounding rock, and consequently the likelihood of an upcoming eruption. Here we show that during the 2011-2016 eruption cycle at Aso volcano in Japan, long-period tremor events, a VLP of $\sim 15 \mathrm{~s}$ period, with opposite waveform polarity can be systematically detected and categorized as pressurization and depressurization events in the same crack-like conduit. We suggest that, depending on the strength of the surrounding rock and the permeability of the crack-like conduit wall/plug, pressurization due to magmatic heat and vaporization is more likely to occur when a less permeable conduit plug/wall can effectively keep the gas inside the crack-like conduit. On the other hand, depressurization is prone to occur if the conduit wall/plug permeability is sufficiently high to allow gas to escape from the conduit. Considering the amplitude of LPT proportional to the conduit overpressure, contrasting energetics of these diverse LPT events allows us to define whether the conduit is prone to pressurization or depressurization, providing a framework to infer how the permeability of the conduit wall/plug may evolve over an eruption cycle.
\end{abstract}

(c) 2020 Published by Elsevier B.V.

\section{Introduction}

Understanding how a volcano works and foreseeing future eruptions are the ultimate goals in volcanology. Recent geophysical, geodetic, geochemical and petrological evidence has pointed to a modern picture of the trans-crustal magmatic system with a lens of crystalrich mush and crystal-poor melt where destabilization and remobilization of such a system lead to an upcoming eruption (e.g., Cashman et al., 2017; Sparks and Cashman, 2017). As an eruption occurs, when the fluid/gas pressure overcomes the strength conduit plug or/and wall, it is of great importance to make a direct assessment of how the conduit strength and pressure vary over eruption cycles, either in a period of apparent quiescence or during unrest before an impending eruption. Conduit pressure is dictated by accumulated gas pressure, which largely depends on magma flow rate, magma viscosity, volatile solubility, and permeability of magma, conduit wall and the formation of conduit plug (Heiken et al., 1988; Jaupart and Allègre, 1991; Woods and Koyaguchi, 1994; Jaupart, 1998; Gonnermann and Manga, 2003;

\footnotetext{
* Corresponding author.

E-mail address: j.niu@ucl.ac.uk (J. Niu).
}

Sparks, 2003; Diller et al., 2006; Burton et al., 2007; Edmonds and Herd, 2007; Okumura et al., 2013; Gonnermann et al., 2017; Heap et al., 2018a). On the one hand, magma degassing can result in bubble nucleation, growth, and coalescence, ultimately forming an interconnected network that governs magma permeability and dictates outgassing. On the other hand, the strength and permeability of a conduit wall/plug could vary against loading size, rate, duration, and temperature (e.g., Benson et al., 2012), crack/fracture network (or porosity), overpressure and heating (e.g., Lavallée et al., 2008, 2013; Okumura et al., 2010; Plail et al., 2014; Gaunt et al., 2016; Heap and Wadsworth, 2016; Heap et al., 2017, 2018b; Kushnir et al., 2017; Bain et al., 2019).

Along with the conduit overpressure, magma and conduit wall/plug permeability seem to be one of the most critical parameters that can help evaluate whether the shallow plumbing system is prone to failure and eruption (e.g., Voight, 1988; Kilburn, 2003, 2018; Sparks, 2003; Hammer and Neuberg, 2009). Not only it governs the ability to withhold gas inside the conduit (e.g., Edmonds and Herd, 2007; Collinson and Neuberg, 2012), it also dictates the mechanical properties (or strength) of the conduit wall/plug and regulates conduit pressure (e.g., Heap and Wadsworth, 2016). On the one hand, the permeability of conduit wall, 
the formation of conduit plug, and the conduit overpressure are intimately linked with magma ascent and outgassing efficiency (e.g., Diller et al., 2006). An increased conduit overpressure may be due to fast gas accumulation, low magma permeability, a stronger and more impermeable conduit wall/plug, resulting in pressurization. Similarly, a decreased conduit overpressure may be due to slow ascent of gassed magma, high magma permeability, or/and a weaker, more permeable conduit wall/plug, resulting in depressurization. On the other hand, high (low) pore pressure can effectively enhance (reduce) permeability (Zoback and Byerlee, 1975; Walsh, 1981; Berryman, 1992; Nara et al., 2011; see also Paterson and Wong, 2005) and such nonlinear feedback or two-way coupling between permeability and overpressure (or effective stress) is probably crucial, but not necessarily included in the simulation (e.g., Diller et al., 2006; Girona et al., 2019). Nevertheless, Understanding such critical parameters and their temporal evolution is needed to help realize physics-based eruption prediction models (e.g., Melnik and Sparks, 1999; Segall, 2013).

In a way, it is important to know how close the overpressure to the strength of the surrounding rock is. If the permeability is low (or the mechanical strength remains high), high overpressure does not necessarily result in the rock failure. Probably, it's a combination of high overpressure and high permeability/low mechanical strength that most likely leads to rock failure and an imminent eruption. While the pressure inside the conduit, to some extent, may be inferred from the activities of volcanic-tectonic earthquakes (VT), volcanic tremors, long-period signals (LP) (e.g., Minakami, 1974; Chouet et al., 1994; Chouet, 1996; McNutt, 1996; Roman and Cashman, 2006) and modeling of ground deformation (Poland et al., 2006; Segall, 2013; Pinel et al., 2014; Fernández et al., 2017; Magee et al., 2018), the permeability of conduit wall/plug and magma are transient in nature and it is nontrivial to infer changes in magma and conduit wall/plug permeability in situ over an eruption cycle. In particular, despite laboratory studies of limited sample size often underestimate the permeability of rock mass in the field, it has demonstrated that the permeability can be modulated by numerous factors, including stress loading cycle, transient variation in pore pressure (Heap et al., 2015; Farquharson et al., 2016), thermal perturbation (Heap et al., 2018b), chemical reaction (Farquharson et al., 2019), and hydrothermal alteration (Heap et al., 2019; Mordensky et al., 2019). Nevertheless, recent efforts suggest that the amplitude of VLP may be linked to the amount of $\mathrm{SO}_{2}$ emissions (e.g., Kazahaya et al., 2011; Nadeau et al., 2011; Waite et al., 2013; Zuccarello et al., 2013), which are potentially modulated by conduit permeability (e.g., Edmonds et al., 2003).

In the following sections, we will first review seismic activities observed near shallow volcanic plumbing systems and highlight signals that are potentially viable for monitoring conduit pressure, focusing on long-period signal (LP) and very long-period signal (VLP). Subsequently, we elaborate our effort in the analysis of VLP events at one of the most active volcanoes in Japan, Aso volcano. In particular, we characterize the variability and diversity of VLP events and construct a catalog documenting how such diverse VLP event families may be utilized to infer conduit permeability and pressure over the 2011-2016 eruption cycle.

\subsection{LP and VLP observations}

Propagation of dikes in the shallow crust, at least for more viscous magma, can result in volcano-tectonic earthquakes (VT) with stress change aligned with pressurization induced by magma movement and diking (e.g., McNutt, 2005; Roman and Cashman, 2006). On the other hand, continuous high-frequency volcanic tremors (0.1-0.2 s), eventlike long-period signal (LP, 0.2-2 s), and very long-period signal (VLP, 2-100 s) can provide constraints on the geometry of the plumbing system and pressure/force variations associated with transient fluid movement (e.g., Chouet and Matoza, 2013). Since LP and VLP are often event-like and repetitive, quantifying their location and source mechanism has offered a basis in delineating the configuration of the shallow magmatic system, providing a platform to build physical models to link these seismic observables to gas/magma movement (e.g., Chouet, 1996, 2009; Chouet, 2003; Kawakatsu and Yamamoto, 2007, 2015; Lees, 2007; Kumagai, 2009; Lane and James, 2009; Neuberg, 2011; Nishimura and Iguchi, 2011; Zobin, 2011; Chouet and Matoza, 2013; Waite, 2014; Jolly et al., 2018) or magma rupture (e.g., Neuberg et al., 2006) in the shallow hydrothermal/magmatic system during volcanic unrest/eruption.

While excitations of $\mathrm{LP}$ ( $1 \mathrm{~s}$ period) can be complicated by the compliance of soft material near the edifice (e.g., Minakami, 1974; Chouet, 1996; Kedar et al., 1996; Bean et al., 2008, 2014), VLP ( 10 s period or longer) is much less susceptible to structural heterogeneities, providing the most unbiased constraint on their source properties. VLP have been reported in many volcanoes around the world, including Asama (Ohminato et al., 2006; Kazahaya et al., 2011; Maeda and Takeo, 2011), Aso (Sassa, 1935; Kikuchi, 1974; Churei, 1985; Kaneshima et al., 1996; Yamamoto et al., 1999; Kawakatsu et al., 2000), Bandai (Nishimura et al., 2003), Hachijo (Kumagai, 2003), Iwate (Nishimura et al., 2000), Miyakejima (Kobayashi et al., 2009; Kumagai, 2001), Ontake (Maeda et al., 2015), Satsuma-Iwojima (Ohminato and Ereditato, 1997), Unzen (Uhira et al., 1994) and Usu (Yamamoto et al., 2002) volcanoes in Japan; Augustine (Dawson et al., 2011), Kīlauea (Dawson et al., 1998), Mammoth Mountain (Hill et al., 2002), Mount St. Helens (Waite et al., 2008), Okmok (Haney, 2010), Redoubt (Haney et al., 2013) volcanoes in USA; Cotopaxi and Tungurahua (Kumagai et al., 2007) in Ecuador; Stromboli volcano (Neuberg et al., 1994) in Italy; Merapi (Hidayat et al., 2000) in Indonesia; Erebus (Rowe et al., 1998; Aster et al., 2003) in Antarctica; Popocatépetl (ArciniegaCeballos et al., 1999) in Mexico; Fuego (Lyons and Waite, 2011) in Guatemala and White Island (Jolly et al., 2017, 2018) in New Zealand.

These VLPs can occur in either eruptive or non-eruptive periods, and they are often associated with unsteady magma and gas transport in the sub-surface volcanic system (see also reviews by Zobin, 2011; Chouet and Matoza, 2013). In some instances, diverse VLP waveforms or VLP event families in a single volcanic system are observed, such as in Kīlauea (Dawson and Chouet, 2014), Stromboli (Chouet et al., 2003), Erebus (Aster et al., 2008), Popocatépetl (Arciniega-Ceballos et al., 2008) and Aso (Kawakatsu et al., 2000). At Kīlauea, three VLP event families with either opposite initial polarities or distinctive spectral peaks are associated with vigorous degassing, rockfall, and pressure decrease of an unknown source (Dawson and Chouet, 2014). In Erebus, VLP event families with distinct initial polarity were related to gas-slug ascent in a variable conduit geometry (Aster et al., 2003).

While the diversity of these VLP events provides key information on processes inside the shallow magmatic or/and hydrothermal systems beneath volcanoes, there is generally a lack of systematic analysis examining how the variability or diversity of VLP in a single volcanic system changes over one or multiple eruption cycles. At Aso volcano, VLP waveforms with opposite polarity are understood as a result of depressurization and pressurization of the shallow conduit near sea level, and they are linked to outgassing and magmatic heating in the same source region (e.g., Kaneshima et al., 1996). Here we first briefly outline the volcanic activity at Aso volcano and the historical observation of VLP events.

\subsection{Aso volcano and 2011-2016 unrest/eruption}

Aso volcano, located in southwest Japan, is one of the most active volcanoes in Japan (Fig. 1). $\mathrm{H}_{2} \mathrm{O}$ concentration in pre-eruptive arc magma beneath Aso volcano is around 2-4 wt\% (Zellmer et al., 2012; Saito et al., 2018), similar to estimates in global subduction zones (e.g., Plank et al., 2013). Aso caldera, a result of four caldera-forming eruptions between 270 and 90 ka (Ono et al., 1995; Hunter, 1998; Kaneko et al., 2007, 2015; Miyoshi et al., 2013; Ishibashi et al., 2018), contains multiple central cones due to post-caldera eruptions in the 


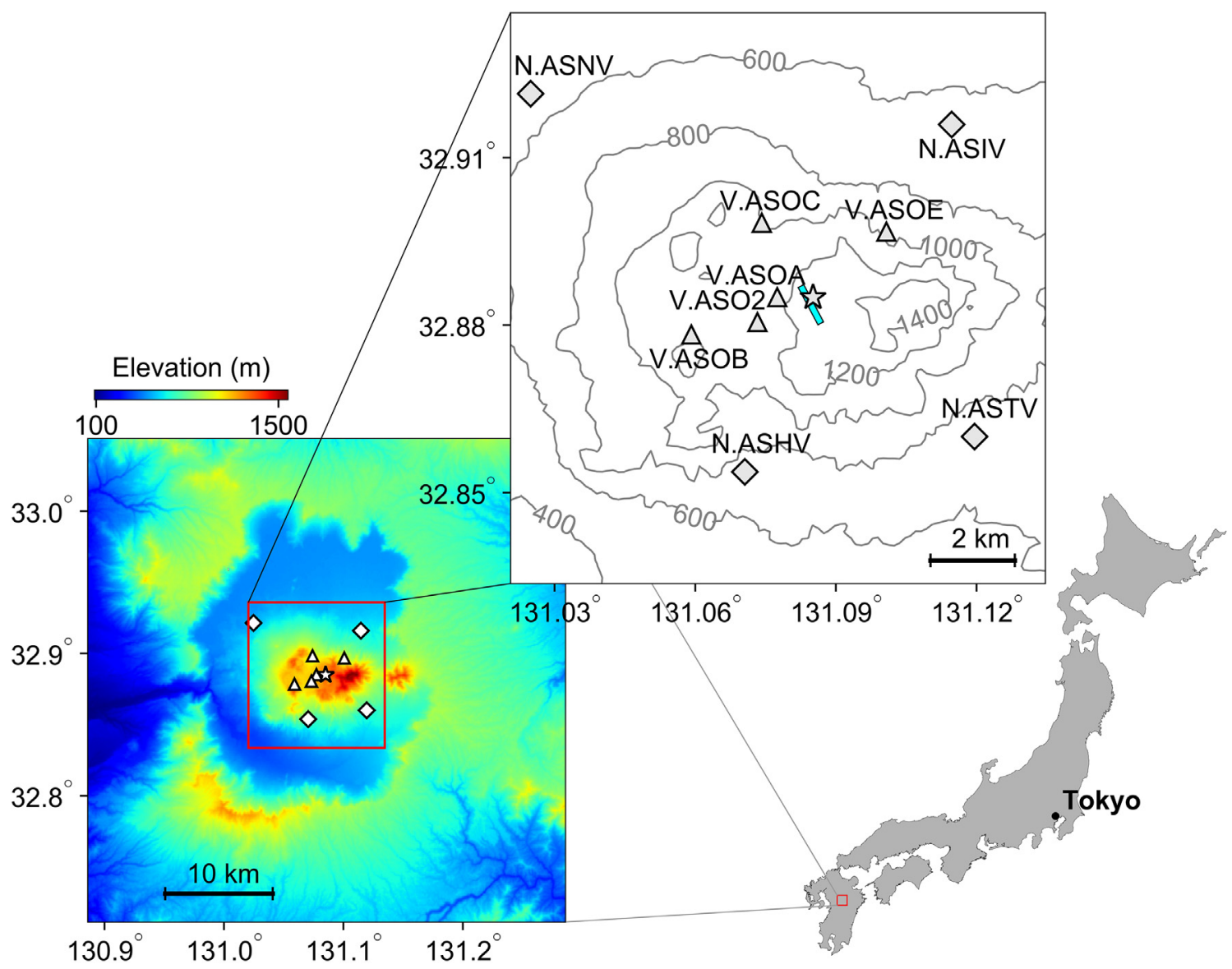

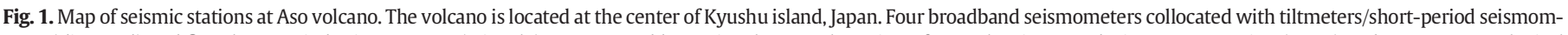

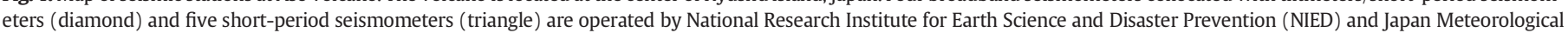

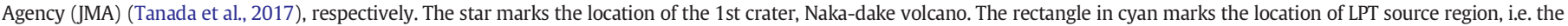
crack-like conduit (e.g., Legrand et al., 2000; Yamamoto et al., 1999).

past 90 ka (e.g., Miyabuchi, 2009, 2011; Miyoshi et al., 2012). Activities in the last 10,000 years are primarily located in the Naka-dake central cone. Since the 1933 eruption, only the northernmost crater, the 1st crater, remains active, and continuous high-temperature fumaroles can be observed in the south wall of the 1st crater (e.g., Ono et al., 1995). Following Sudo et al. (2006), we briefly summarize the characteristic volcanic activities of the 1 st crater.

Typically, surface volcanic activities follow a cycle starting with a period of quiescence and the presence of the crater lake. During the initial unrest, minor phreatic eruptions or/and mud-eruptions can occur. The disappearance of the crater lake is superseded by red glows at the crater bottom, followed by ash emission and ultimately Strombolian eruption, whereas phreatic, phreatomagmatic or/and explosive eruptions can also occur (e.g., Miyabuchi et al., 2006; Ikebe et al., 2008), often during the recovery of the crater lake or/and the end of the eruption cycle (e.g., Sudo et al., 2006). Presumably, the magmatic heat and input of hot volcanic fluids (e.g., Terada et al., 2012; Shinohara, 2013) originate from a deep conduit or/and a magma chamber at 6-7 $\mathrm{km}$ depth (e.g., Sudo and Kong, 2001; Sudo et al., 2006) and possibly even deeper below $10 \mathrm{~km}$ depth (e.g., Abe et al., 2010, 2017; Unglert et al., 2011). The fact that the level of the crater lake fluctuates drastically is evidence of continuous and substantial thermal energy feeding from below.

In the case of the 2011-2016 eruption cycle, except minor phreatic eruptions in May 2011 and late 2013, Aso volcano was generally in quiescence. However, the temperature measured on the south wall of the crater shows a remarkable increase from about $60^{\circ} \mathrm{C}$ to about $240{ }^{\circ} \mathrm{C}$ between mid-2011 to mid-2012, steadily rising to about $300{ }^{\circ} \mathrm{C}$ by late 2012. The total magnetic intensity measured near the 1 st crater indicates demagnetization between December 2010 and October 2012, also supporting a temperature rise underneath the crater (see also Tanaka, 1993). In the meantime, the crater lake level decreased from mid-2010 and dropped to a very low level in mid-2011 and mid2012 before recovering in the next few months, respectively. The crater lake level again decreased to a very low level from March 2013 to late 2013. In general, the $\mathrm{SO}_{2}$ emission remained mostly at the background level of 200-400 tons/day during 2011-2013.

In January-February 2014, a few small ash emissions occurred and the $\mathrm{SO}_{2}$ emission increased from the background level to $1000-3000$ tons/day in early 2014 . The crater lake began to dry up in July 2014, and the temperature measured at the crater bottom increased rapidly from $300{ }^{\circ} \mathrm{C}$ to about $600{ }^{\circ} \mathrm{C}$. At the end of August 2014 , ash eruptions occurred, and intermittent Strombolian eruptions took place from the 25th November 2014 until the beginning of May 2015 (Yokoo and Miyabuchi, 2015; Miyabuchi and Hara, 2019), when the southern part of the pyroclastic cone collapsed. Since then, the crater lake has recovered and remained at a very low level, and the $\mathrm{SO}_{2}$ emission remained high throughout the rest of 2015 and most of 2016. Besides several minor phreatic/ash eruptions, a phreatomagmatic eruption with a small-scale pyroclastic density current occurred on the 15th September 2015 (Miyabuchi et al., 2018), and another phreatomagmatic explosion, preceded by elevated $\mathrm{SO}_{2}$ emission ( $>10,000$ tons/day), occurred on the 8 th Oct 2016, where the plume height reached about $12 \mathrm{~km}$ above sea level (Ishii, 2018; Ishii et al., 2018; Sato et al., 2018). After the October 2016 eruption, the crater lake level gradually recovered, effectively marking the end of the 2011-2016 eruption cycle. 


\subsection{VLP observed in Aso volcano}

VLP was first reported by Sassa in 1935 (Sassa, 1935), and it was categorized as volcanic micro-tremors of the second kind, with a period of 5-8 s. More recently, Kawakatsu and co-workers (e.g., Kaneshima et al., 1996; Yamamoto et al., 1999; Kawakatsu et al., 2000; Legrand et al., 2000) analyzed broadband seismic data of several months in 1994 and systematically characterized VLP spectra and source properties. Since long-period tremor, or LPT, was first termed by Kawakatsu and coauthors to discuss VLP signal in Aso volcano and it has been widely recognized in the community, we use the same nomenclature hereafter for consistency.

As documented by Kawakatsu et al. (2000), LPT typically has a duration of $60 \mathrm{~s}$ and a dominant period of $\sim 15 \mathrm{~s}$, with secondary spectral peaks at $7.5 \mathrm{~s}, 5 \mathrm{~s}$, and $3 \mathrm{~s}$, respectively. Moment tensor inversion indicates that LPT is located at $\sim 200 \mathrm{~m}$ southwest of the first crater near sea level. It corresponds to a low seismic velocity (Huang et al., 2018) and a modestly high conductivity zone (e.g., Hase et al., 2005; Hata et al., 2016, 2018; Kanda et al., 2019), most likely a region of a hydrothermal reservoir. The source of LPT is predominantly isotropic (>90\%) with a minor tensile crack component (Kawakatsu et al., 2000; Legrand et al., 2000) and their excitation is generally considered as a result of fluid-solid interaction triggered by a transient pressure change in a crack-like conduit (e.g., Yamamoto et al., 1999; Kawakatsu et al., 2000; Kawakatsu and Yamamoto, 2007).

The crack-like conduit is often regarded as a pathway transporting hot gas toward a shallower hydrothermal system below the crater bottom (e.g., Hase et al., 2005; Takagi et al., 2006; Kawakatsu and Yamamoto, 2007; Kanda et al., 2008, 2019; Minami et al., 2018). Notably, high-frequency signals or/and LP-type events, at least in some instances, also occur in sync with LPT and fumarole activities (e.g., Sassa, 1935; Kikuchi, 1974; Churei, 1985), suggesting a causal fluid/pressure connectivity between the crack-like conduit at sea level and surface volcanic activities (e.g., Ichimura et al., 2018; Kawakatsu and Yamamoto, 2007; Mori et al., 2008; Takagi et al., 2006, 2009). In general, the LPT waveform starts with a negative initial polarity and it was generally interpreted as a result of the rapid release of the liquid-gas mixture through fractures (Kaneshima et al., 1996; Kawakatsu et al., 2000). LPT waveform with a positive initial polarity was occasionally recognized during phreatic eruptions in 1993-1994, and it was typically regarded as a result of rapid pressurization due to vaporization induced by magmatic heat and supply of hot fluid/gas from below (Kaneshima et al., 1996; Kawakatsu et al., 2000).

As detailed above, while the early investigation of Kaneshima et al. (1996) and Kawakatsu et al. (2000) documented LPT waveforms of opposite polarity, it was limited to a quiet period of volcanic activity where occasional phreatic eruptions occurred in the presence of the crater lake. The diversity of LPT families during active periods, however, was unknown. In a way, it is unclear how the variability of LPT waveforms, polarity, and their activities can be understood concerning the entire eruption cycle of Aso volcano. Given the latest development of the fundamental volcano observation network, or V-net (Tanada et al., 2017), as well as the existing volcanic network from Japan Meteorological Agency (JMA), the 2011-2016 eruption cycle offers an ideal framework to systematically explore the diversity of LPT and their temporal evolution against the entire eruption cycle. In particular, not only does it allow an assessment of the state of the shallow plumbing system during low surface activities in the early stage of the eruption cycle, but it also presents an unprecedented opportunity to examine and explore how diverse LPT families and their respective activities vary from a period of volcanic quiescence to active episodes of Strombolian or/and phreatomagmatic eruptions.

In the following sections, we document the systematic detection and characterization of the diverse LPTs. After briefly outlining the data and seismic network in Section 2, we describe the methodology to detect and construct a catalog of diverse LPT families in Section 3. In particular, we report the identifications of several LPT families using the continuous wavelet transform (CWT) and the matched-filter (MF) analysis. In Sections 4 and 5, we highlight the temporal variation in the activities of these diverse LPT families and elaborate on how these new observations can be used to infer the temporal change of the state of crack-like conduit and surface volcanic activities. In particular, we contrast the energetics of these LPT families and suggest a simple metric to assess when the conduit is prone to pressurization or depressurization, allowing us to infer variations in conduit wall/plug permeability over the eruption cycle.

\section{Data}

Since late 2010, National Research Institute for Earth Science and Disaster Prevention (NIED) in Japan began establishing the fundamental volcano observational network, $\mathrm{V}$-net, across active volcanoes (Tanada et al., 2017). By 2017, 16 active volcanoes are equipped with V-net. At Aso volcano, V-net includes four collocated surface broadband seismometers, borehole short-period seismometers, and tilt-meters, typically a few kilometers away from the 1st crater (Fig. 1). The stations ASIV and ASHV have been available since 2011, whereas the stations ASTV and ASNV have become available since 2016 (see also Fig. S1). While V-net typically includes collocated GNSS stations, these data are not yet made publicly available. Nevertheless, coupled with the five existing short-period seismometers from JMA Volcanic Seismometer Network, it constitutes an ideal seismic network to conduct a systematic analysis of the diversity of LPT and their activities over the 2011-2016 eruption cycle (Fig. 1). Broadband seismometers of V-net are equipped with a Nanometrics-240 sensor (e.g., 250 s natural period), which is comparable to the bandwidth of the broadband seismic network F-net deployed by NIED across Japan. On the other hand, the natural period of short-period seismometers of JMA is about $1 \mathrm{~s}$.

While data from broadband stations ASHV and ASIV are ideal to detect LPT of a $15 \mathrm{~s}$ dominant period, the capability of the short-period sensor in recovering long-period signals depends largely on the quality of the data and signal-to-noise ratio. Among the short-period stations, except ASO2, other short-period stations are noisy below $5 \mathrm{~s}$ (Fig. S2). Furthermore, we calibrate the sensor misorientation against longperiod $\mathrm{P}$ wave particle-motion, following the approach of Lim et al. (2018) and examining the amplitude of tangential receiver functions at zero time. Typically, the estimated sensor misorientation is less than $\pm 3.0^{\circ}$ (see also Supplementary material). After correcting sensor misorientation, we carefully examine the amplitudes of low-frequency modes (Davis et al., 2005) and long-period surface waves (Ekstrom et al., 2006) from large earthquakes. Among V-net broadband seismometers and nearby F-net seismometers, the amplitudes are consistent within $\pm 3 \%$, indicating the consistency of their sensor gains (see also Supplementary material).

As detailed below in Section 3, after considering data quality, data gap, and continuity, three high-quality vertical channels from ASHV, ASIV, and ASO2 are used for initial LPT detection. Once the initial detection is made, three-component waveforms of LPT are stacked to form 9channel waveform templates for the final detection. Since data from ASO2 are not available between December 2013 and April 2014 (Fig. S1), the detection capability is notably compromised in this period. In the following section, we detail the method of LPT detection and report the discovery of several LPT families and the pattern of their activities.

\section{Method and detection of diverse LPT families}

To conduct a systematic analysis of the diversity of LPTs at Aso, our approach involves three major steps and the workflow is presented in Fig. 2. First, we conduct a visual inspection and construct a robust LPT waveform template. Secondly, we perform an automatic detection in the continuous wavelet transform (CWT) domain, capable of identifying 


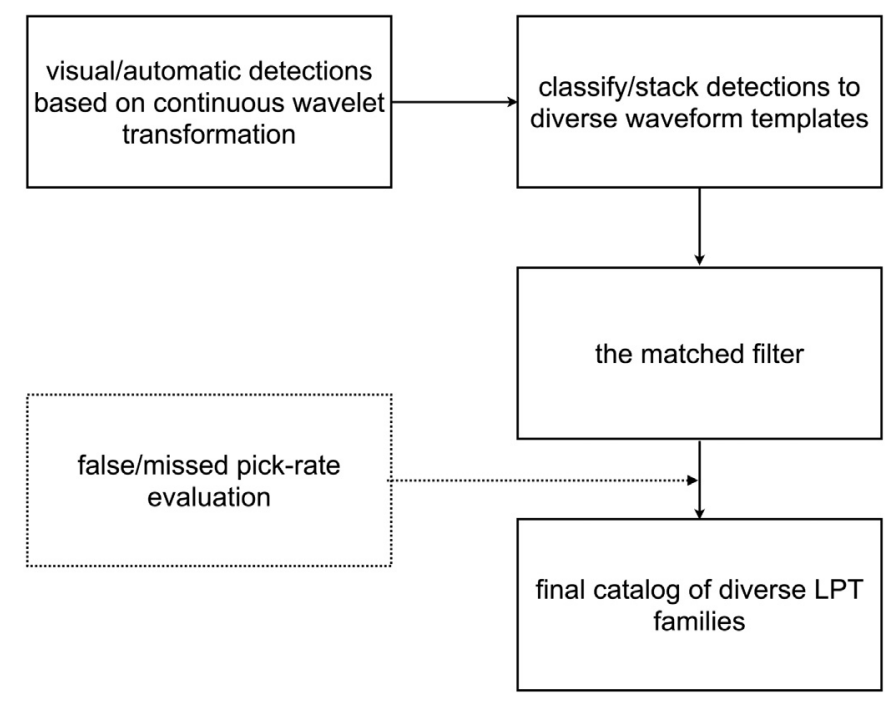

Fig. 2. LPT detection/classification workflow. It consists of the visual detection of the initia template, the automatic detection of waveform templates based on continuous wavelet transformation (CWT), the template classifications, and the complete catalog construction using the matched filter (MF). The final catalog is obtained by evaluating the rate of false detection against cross-correlation coefficient $(\mathrm{CC})$ and signal-to-noise ratio (SNR) thresholds (see main text).

diverse LPTs. These initial LPT detections are evaluated, classified, and subsequently stacked to form LPT waveform templates. Thirdly, with the LPT waveform templates, we apply the matched filter (MF) against continuous-waveform data to construct the catalog of such diverse LPT families during 2011-2016. To appreciate the performance of the MF method and evaluate potential false/missed LPT identification, we perform the MF against a synthetic LPT catalog and examine the false/ missed pick rate against signal-to-noise ratio (SNR) and cross-correlation (CC) coefficient thresholds, which provides an objective selection criterion to assess the robustness of LPT detections and their activities. Hereafter, we document the data processing procedures.

\subsection{Initial LPT template}

To build a robust LPT template for automatic detection, we first perform the CWT to inspect LPT activities in Oct 2014, during which surface volcanic activity is prominent. Compared with the short-time Fourier transform, CWT does not require a pre-defined window size and can perform local analysis on a non-stationary signal (Grossmann and Morlet, 1984; Mallat, 2009). The continuous time series is first sliced into ten-minute long windows and the instrument response removed. Velocity seismograms in each slice are simultaneously examined in the time domain, frequency domain, and CWT time-frequency domain in the frequency band of $0.02-2 \mathrm{~Hz}$ (e.g., Fig. 3). After visually inspecting over 9000 windows, we recognize hundreds of isolated wave packets with strong amplitudes in the vertical and radial components, oscillating $<60 \mathrm{~s}$ in the time domain and displaying two dominant spectra peaks at the periods of about $15 \mathrm{~s}$ and $7.5 \mathrm{~s}$, all diagnostic features of LPTs. The waveform amplitude also decreases from ASO2 to ASIV and ASHV, consistent with an LPT source located close to the 1st quarter. In the subsequent CWT automatic detection scheme, we use the waveforms in the vertical component of stations ASO2, ASHV, and ASIV as the initial LPT waveform template.

\subsection{CWT automatic identification of LPT}

Having constructed the LPT waveform template, an automatic detection scheme is carried out by CWT and cross-correlation method against the 6-year continuous data. The waveform template and a continuous data window of $2 \mathrm{~min}$ are first decimated to $10 \mathrm{~Hz}$, with the instrument response removed and normalized before calculating the CWT spectrograms and the time-frequency-amplitude map (TFAM). We compute a 2D cross-correlation between template TFAM and data TFAM. If the average cross-correlation coefficient is over 0.8 , we mark the identification of LPT as well as its timing (Fig. 4). Data windows are shifted $12 \mathrm{~s}$ and the same process is repeated. In our approach, it is important to ensure that the detection scheme is robust but flexible enough to identify LPTs with diverse waveform shapes, opposite polarity, or/and variable spectra peaks. Therefore, the phase information is not utilized at this stage. Furthermore, we use fifty frequency points in the band of $0.02-2 \mathrm{~Hz}$ to ensure the resolution of the spectrogram and the constraint for detection.

Several stringent criteria are used to remove possible false detections and ensure high-quality detection. First, if the average amplitude ratio between the unfiltered seismogram and the filtered seismogram $(10-30 \mathrm{~s})$ of the three different channels is over 13 , the detection is removed (Rejection criterion I). While the threshold of amplitude ratio is admittedly somewhat arbitrary, it warrants strong, long-period energy and quality LPT detection. Secondly, to remove duplicate LPT detection within a 2-min data window, we keep the detection only if $95 \%$ or more of the waveform energy concentrates in the central $30 \mathrm{~s}$ (Rejection criterion II). Thirdly, since LPT is located about $200 \mathrm{~m}$ southwest of the 1 st crater, we expect the amplitude decays quickly away from ASO2 in the near field. Therefore, we retain LPT detections only if the maximum amplitude at ASO2 is at least 1.5 times greater than the maximum amplitude at ASHV and ASIV (Rejection criterion III). This eliminates false identifications where the source of energy originates far away from the 1 st crater or the known LPT source location (e.g., Kawakatsu et al., 2000; Legrand et al., 2000).

Out of about 87,000 initial detections, $90 \%$ of the initial detections fail to pass these three rejection criteria and are removed. Finally, we perform an additional visual inspection over the remaining detection and remove several false detections caused by the calibration pulses from the short-period channel ASO2. The final number of LPTs detected by the automatic CWT scheme is 7455 and the detection threshold at the station ASHV is about $0.1 \mu \mathrm{m} / \mathrm{s}$.

\subsection{Identification of diverse LPT families}

Following the CWT detection of LPTs, we systematically examine the stability/variety of LPT waveform shapes in a 30-day moving window with an overlap of 15-days. In many instances, LPT waveforms within a 30-day time window are quite similar and there are up to hundreds of LPTs during the active period between late 2014 and late 2015. Figs. 5a-d and S3 display typical LPT waveforms in September 2014, October 2014, October 2015, and November 2015 and we classify these four LPT waveform families as LPT-A, LPT-B, LPT-C, and LPT-D, respectively. Notably, the initial polarity of LPT-A is positive, and LPT-B/C/D are consistently negative. Waveforms of LPT-A are anti-correlated with waveforms of LPT-B, LPT-C, and LPT-D (cross-correlation coefficient of $-0.93,-0.79$ and -0.88 , respectively). On the other hand, we can observe that the waveforms of LPT-A and LPT-B are nearly symmetric but anti-correlated, whereas the waveforms of LPT-C and LPT-D are asymmetric, suggesting an energy interference between the main spectral peak near $15 \mathrm{~s}$ and the secondary peak at about $7.5 \mathrm{~s}$ are not uniform among these LPT families (Fig. 5e-h). In the next section, three-component waveform stacks of these 4 LPT families from ASO2, ASHV, and ASIV will be fed into the MF scheme to detect their activities in the 2011-2016 eruption cycle.

\subsection{Detection of diverse LPT families in 2011-2016 with the MF}

As demonstrated in previous sections, our CWT-based automatic detection is effective in picking quality LPT with high SNR. However, the detection threshold is high, and we potentially miss many weak LPTs. A more sensitive detection scheme, the multi-channel matched filter 

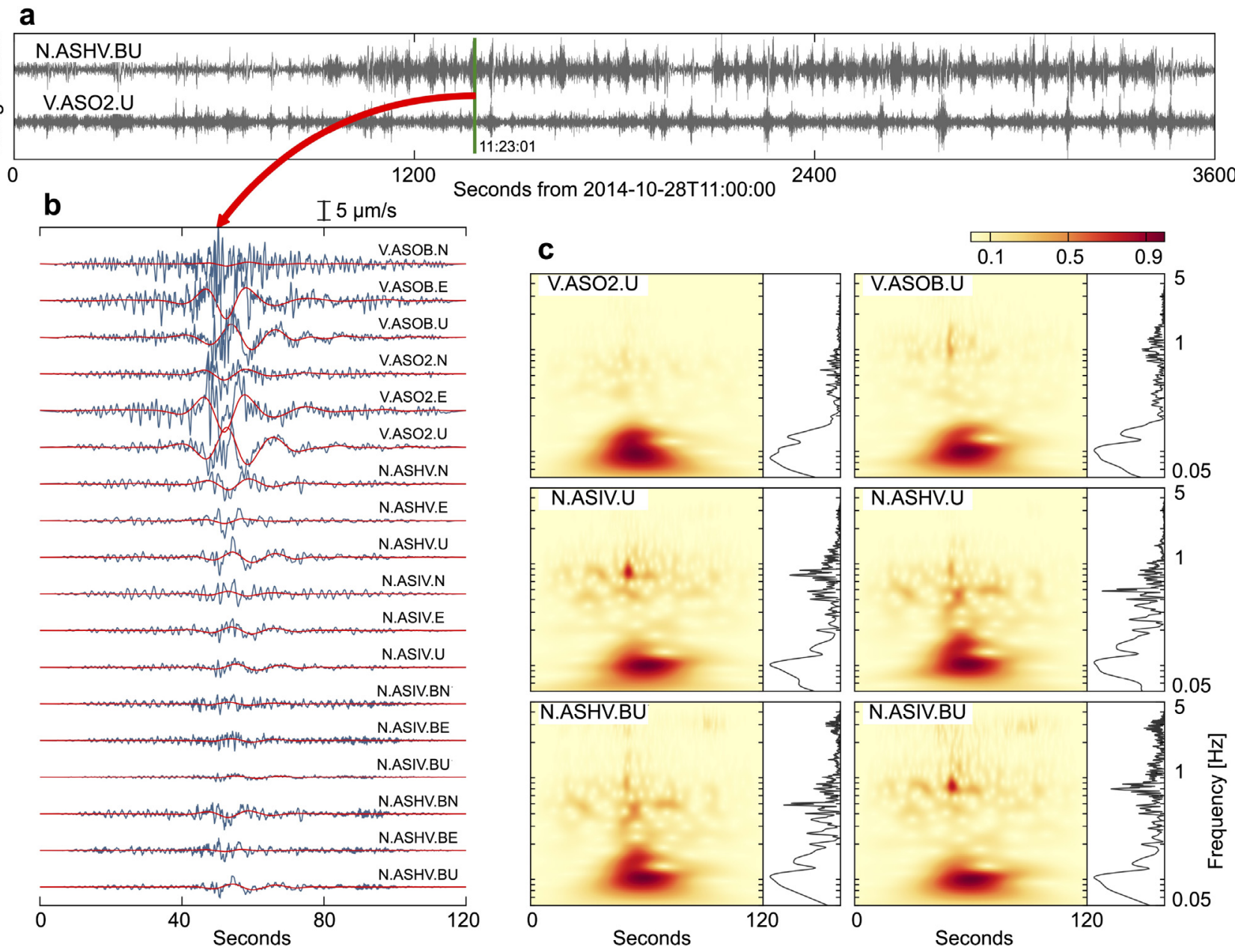

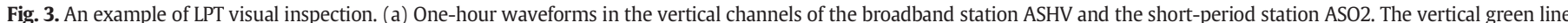

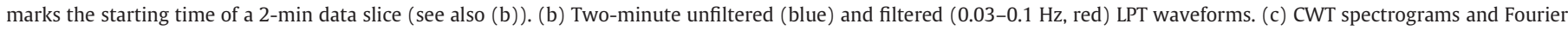

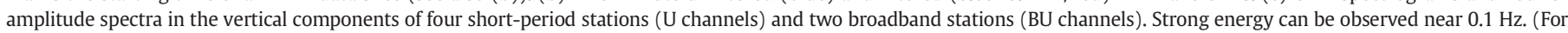
interpretation of the references to colour in this figure legend, the reader is referred to the web version of this article.)

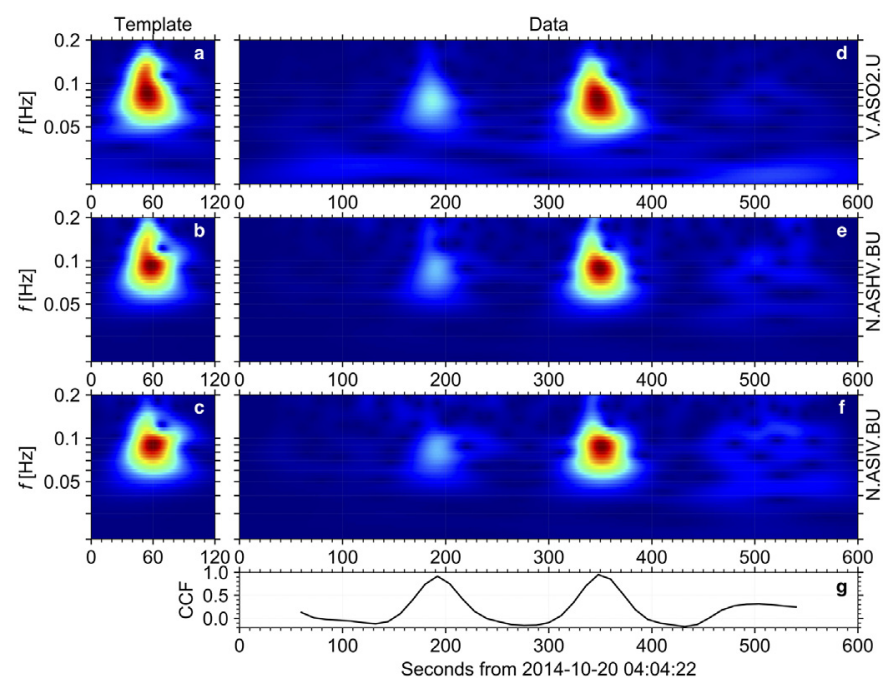

Fig. 4. An example of TFAM cross-correlation and LPT detection. Time-frequency amplitude maps (TFAM) calculated by CWT on the 10-min waveforms of two vertical broadband channels (N.ASHV.BU and N.ASIV.BU) and a vertical short-period channel (V. ASO2.U) are presented. The average cross-correlation functions between the data TFAMs (upper panels) and the template TFAMs (lower panels) are shown in the bottom panel. Two detections can be identified near $170 \mathrm{~s}$ and $330 \mathrm{~s}$ where the cross-correlation peaks mark their onsets.
(MF) is a powerful technique that can help extract weak but coherent signals embedded in the noise using pre-defined templates (Turin, 1960), such as low-frequency earthquakes in subduction zones (e.g., Shelly et al., 2007) and LPT in Aso volcano (Ikeda, 2005). Here we adapt the MF scheme to improve the detection capability against the aforementioned diverse LPT families.

Specifically, in a period band of 10-30 s, we cross-correlate the data against each LPT template in a 2-minute moving window and compute the averaged CC function across 9 channels (Fig. 6). We disregard CC functions with negative peaks and a detection/classification is made against the remaining CC functions with the highest peak amplitude. Concerning a typical LPT waveform of $60 \mathrm{~s}$, if there are multiple identifications within a 30-second window, the detection with the highest CC peak is retained, effectively removing redundant picks. Finally, we apply the Rejection criterion III previously introduced in the CWT automatic detection scheme to remove detections that are not consistent with the source location of LPT.

Before discussing the result of MF-based detection of LPTs in 2011-2016, it is useful to examine the capability of the detection scheme in detecting and classifying diverse LPT families. In particular, the construction of an MF-based catalog depends on the CC threshold and the minimum time separation of neighboring events. In particular, if the amplitude cutoff of the CC is too low, numerous false detections may occur. If two neighboring events occur too close in time, we may potentially miss one of the two events. Therefore, we construct a synthetic catalog by using four families of LPT waveform templates to 

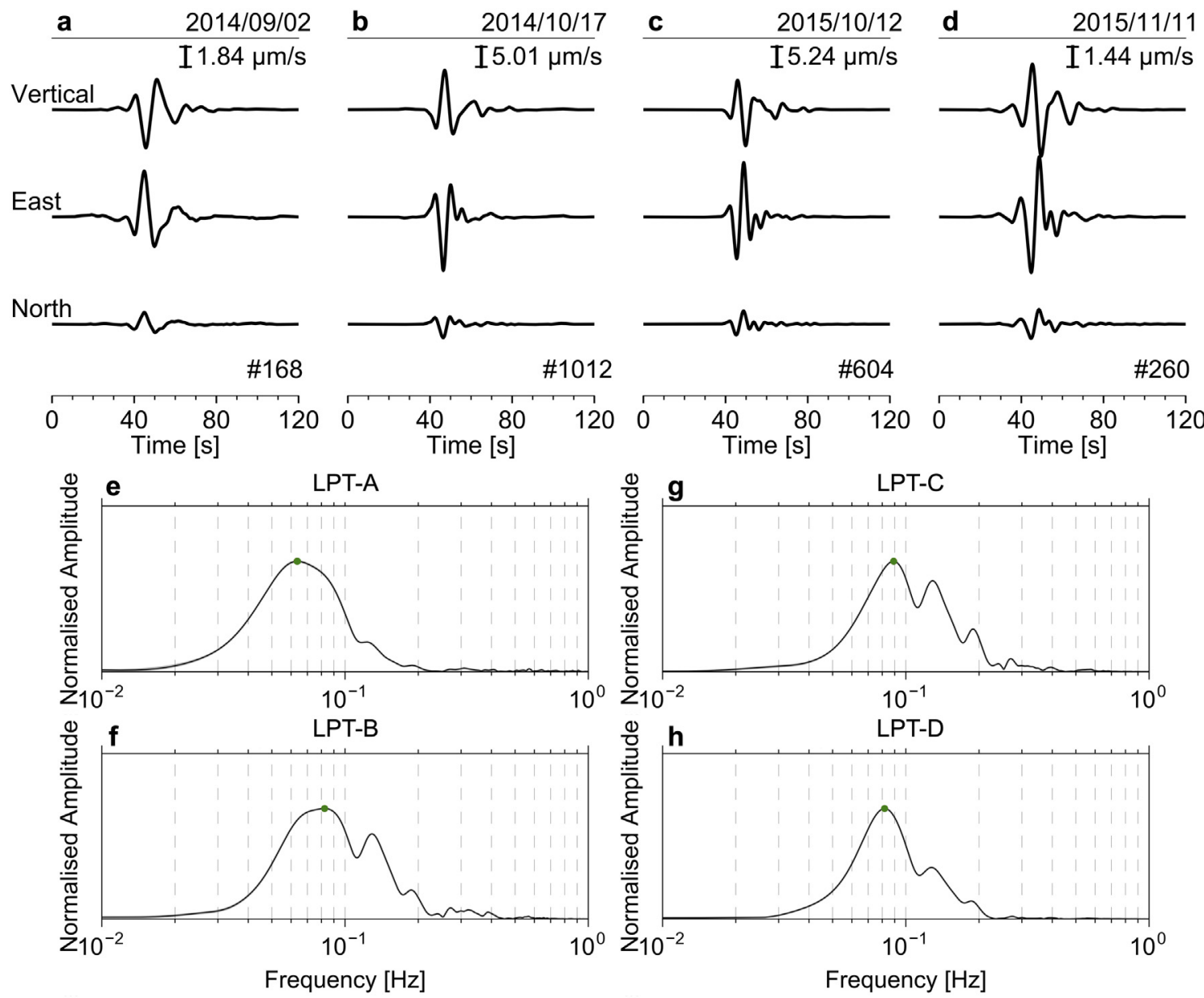

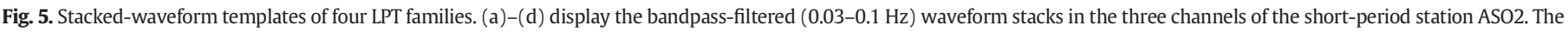

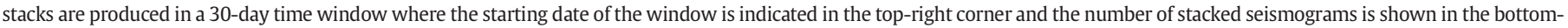

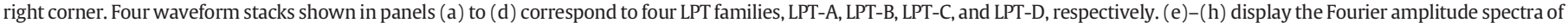

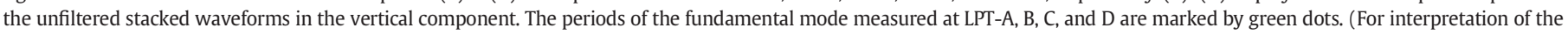
references to colour in this figure legend, the reader is referred to the web version of this article.)

examine the false-pick rate against SNR and CC thresholds in these two scenarios. As shown in Fig. S4, the MF worked reasonably well even when SNR and CC are low. With CC $\geq 0.45$ and $S N R \geq 1.8$, the percentage of correct picks can reach $99 \%$ and the percentage of false picks or misidentifications is near $1 \%$. With CC $\geq 0.63$ and SNR $\geq 2.92$, the correct picks reach above $99.9 \%$, the misidentifications are about $0.1 \%$. Our MF scheme detects 2,740,745 events during 2011-2016, and with the criteria of $C C \geq 0.63$ and SNR $\geq 2.92$ and a nominal false-pick rate of $0.1 \%$, we retain 208,518 events in the final catalog. This ensures the robustness of LPT event classification, allowing us to elaborate and contrast the activities of different LPT families over the eruption cycle.

\section{Activities of LPT families and surface activities during the 2011-2016 eruption cycle}

\subsection{Location of LPT families and temporal change?}

To understand how the activities of LPT families may vary against surface volcanic activities, we first produce monthly waveform stacks of these LPT families at the closest station ASO2 and examine the temporal variations of their particle motions. As shown in Fig. 7, not only are the polarizations of these LPT families consistent with each other, but they also display relatively minor differences during 2011-2016, indicating a limited variation in depth or location by $\sim 100 \mathrm{~m}$. It appears that the depth of LPT during the quiescent period of 2011-2013 is slightly deeper than that during the unrest and active period of
2014-2016. On the other hand, the particle motion of these LPT families is well reproduced by the source location and mechanism reported by Kawakatsu et al. (2000) and Legrand et al. (2000). The consistency also indicates that the source locations of these LPT families are not only in very close proximity during the 2011-2016 eruption cycle, but they also remain stable and consistent with the LPT source properties defined during a relatively quiet episode of low surface volcanic activity in the 1990s (e.g., Kawakatsu et al., 2000). While Hendriyana and Tsuji (2019) reported that LPT appears to migrate significantly after the 2016 Kumamato earthquake, steady polarization observed across the entire 2011-2016 eruption cycle does not support such a finding.

\subsection{Activities of diverse LPT families during 2011-2016 eruption cycle}

To explore how the activities of LPT families may correspond to surface volcanic activities, we first examine their median amplitudes and weekly numbers (Fig. 8). The weekly amplitude of these LPT families is typically weak at $\sim 0.2 \mu \mathrm{m} / \mathrm{s}$ during the period of relative quiescence between 2011 and early 2014. By July 2014, their amplitude increases rapidly, peaking at $\sim 5 \mu \mathrm{m} / \mathrm{s}$ in early 2015, when intermittent Strombolian eruptions occurred. However, except for the short episodes of two notable phreatomagmatic eruptions in September 2015 and October 2016, the amplitude of these LPT families after the Strombolian eruption activity is generally steady at about $0.5 \mu \mathrm{m} / \mathrm{s}$, about a factor of 2 of the pre-eruptive level before mid-2014. Most notably, the 
a
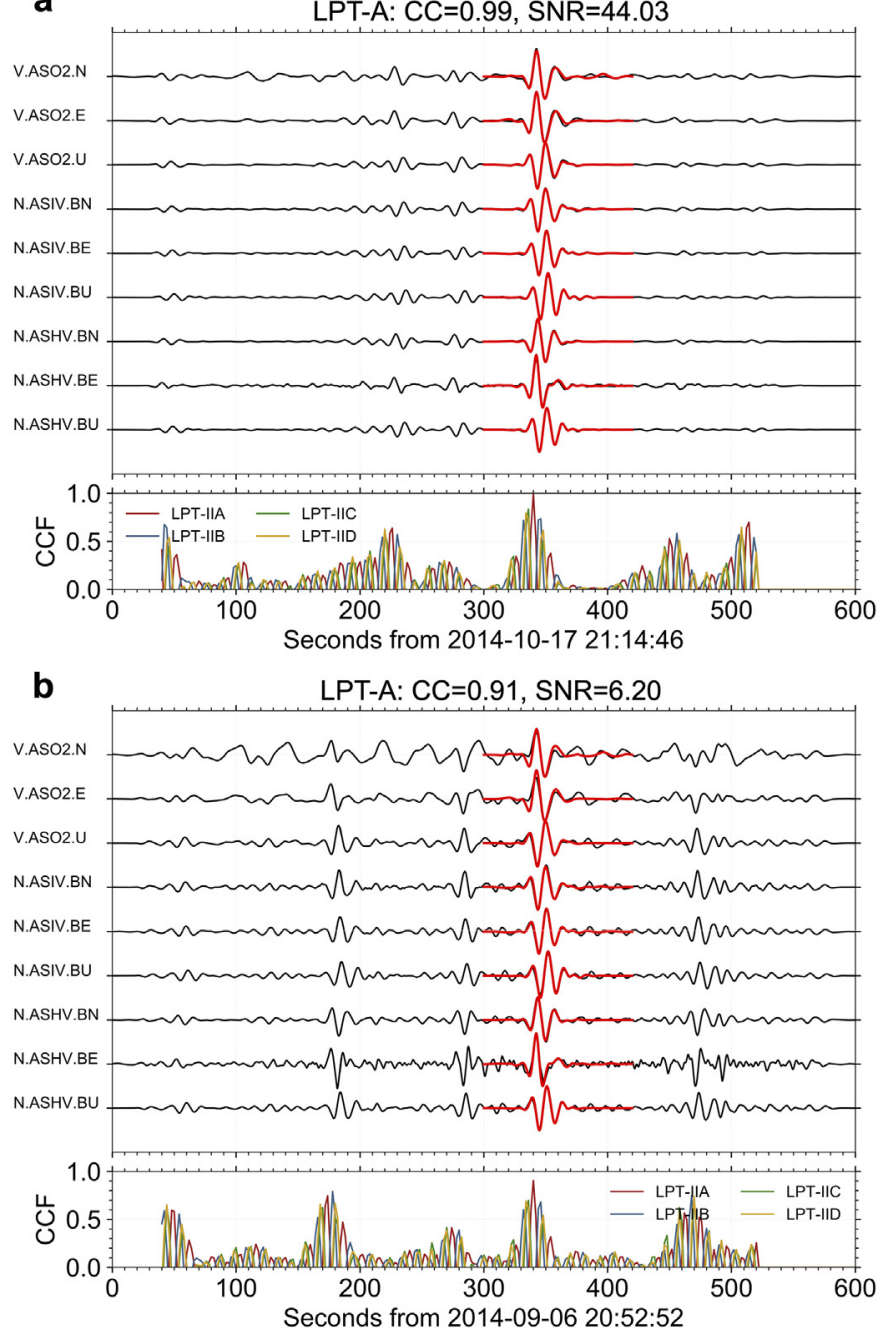

Fig. 6. An example of waveform cross-correlation and LPT detection using the matched filter (MF). (a) Waveform cross-correlations between the 10-min data waveforms (black) and LPT waveform templates from two broadband stations (N.ASIV.BU and N. ASHV.BU) and a short-period station (V.ASO2.U). Cross-correlation functions between the data and the four LPT waveform templates are presented in the lower panel. The waveform templates of LPT-A (red) show the highest cross-correlation against data waveforms at $\sim 340 \mathrm{~s}$ (cross-correlation coefficient, CC, of $\sim 0.99$ and signal-to-noise ratio, SNR, of $\sim 44$ ). (b) is the same as (a), but with an LPT detection of lower SNR ( 6.20). (For interpretation of the references to colour in this figure legend, the reader is referred to the web version of this article.)

amplitudes of these LPT families are comparable and they generally vary consistently during the 2011-2016 eruption cycle (Fig. 8b).

In contrast, the weekly numbers of these LPT families do show a considerable difference, and these observations do not depend on the choice of false-pick rate threshold (Figs. 8, S5). In particular, during the period of relative quiescence between 2011 and early 2014, the level of activities of LPT-A and LPT-B is generally comparable, with minor activities between mid-2012 and early 2013 (Figs. 8, see also S5). However, the activities of LPT-C and LPT-D are very low during this period. Between mid-2014 and the end of 2016, we identify several important features distinguishing the activities of these LPT families. Typically, LPT-A consistently becomes very active 1-3 months before the magmatic eruptions (e.g., November 2014 Strombolian eruption, September 2015 phreatomagmatic eruption, and 2016 phreatomagmatic explosion). Secondly, days to weeks before magmatic eruptions and other minor eruptions, LPT-B is typically quite active, and these eruptions frequently occur as the activities of LPT-B are in decline. Thirdly, the activities of LPT-C and D mostly begin after mid-2014, and their activities also peak days to weeks before several minor eruptions in 2015 and 2016. Overall, the level of activity between LPT-A and LPT-B/C/D over the 2011-2016 eruption cycle is about 1:2 (Fig. S6).

\subsection{Classify the activities of LPT families against surface volcanic activities in the 2011-2016 eruption cycle}

Since the noise level and the detection threshold at any given time are the same among all LPT families, the systematic differences in their activities discussed in Section 4.2 probably manifest genuine differences in the state of the shallow crack-like conduit, dictating surface volcanic activities over the 2011-2016 eruption cycle. Following the discussions above, we elaborate on the activities of these diverse LPT families concerning surface volcanic activities and classify the activities of LPT families into three phases. To highlight the episodes of elevated LPT activities compared with the background, we define the time windows when the weekly number of LPTs exceeds the average weekly number over an 8-week long time window, indicating the episodes where LPT-A or LPT-B/C/D activities are particularly elevated.

As shown in Fig. 8, Phase 0 is marked by the generally weak and low LPT activities associated with low surface volcanic activities during the period of relative quiescence between 2011 and mid-2014. Phase 1 marks the episodes of elevated LPT-A activities weeks-to-months before the major eruptions involving juvenile magmas in November 2014 (Strombolian), September 2015 (phreatomagmatic), and October 2016 (phreatomagmatic). Phase 2a proceeds after phase 1 and marks the episodes of elevated LPT-B/C/D activities of high amplitude before the major eruptions. On the other hand, phase $2 \mathrm{~b}$ marks the elevated LPT-B/C/D activities of low amplitude, typically followed by minor, non-magmatic (e.g., phreatic, mud eruptions) in 2016. Notably, phase 1 , phase $2 \mathrm{a}$, or phase $2 \mathrm{~b}$ are not necessarily a single, continuous phase and they can include multiple time windows (or episodes) before each eruption.

While the definition of elevated LPT activities is not unique, our classification scheme provides a useful way to coherently relate the activities of diverse LPT families to surface volcanic activities. In the following discussions, we summarize our observational findings and provide plausible mechanisms that link the activities of diverse LPT families near sea level to surface volcanic activities in Aso volcano. In particular, we use the observed attributes of diverse LPT families to discuss the inferences on the evolution of overpressure and wall/plug rheology in the crack-like conduit during the 2011-2016 eruption cycle.

\section{Discussions}

5.1. Diverse LPT families: magmatic heating vs. outgassing; pressurization vs. depressurization

Here we document new findings of the four LPT families which are closely located during the 2011-2016 eruption cycle. As discussed in previous studies (e.g., Kaneshima et al., 1996; Kawakatsu et al., 2000), moment tensor inversion of LPT waveforms highlights a source of predominantly volume (or pressure) change in the crack-like conduit. It not only buffers the upward heat transport from a deep-seated magma chamber but also leaks gas or liquid up toward the crater lake or/and pathways toward surface fumarolic activities (e.g., Mori et al., 2008). Intermittent supply of hot fluids from the deep conduit or magma chamber can result in vaporization and a pressure increase in the crack-like conduit, producing LPT-A with a positive initial polarity. A transient upward leakage of gas out of the hydrothermal reservoir and a sudden pressure drop may drive the crack-like conduit to resonate, resulting in LPT B/C/D families with a negative initial polarity. Therefore, we regard the LPT-A family as a proxy of the transient pressurization episode and LPT-B/C/D families as a proxy of depressurization episode and outgassing in the crack-like conduit. 

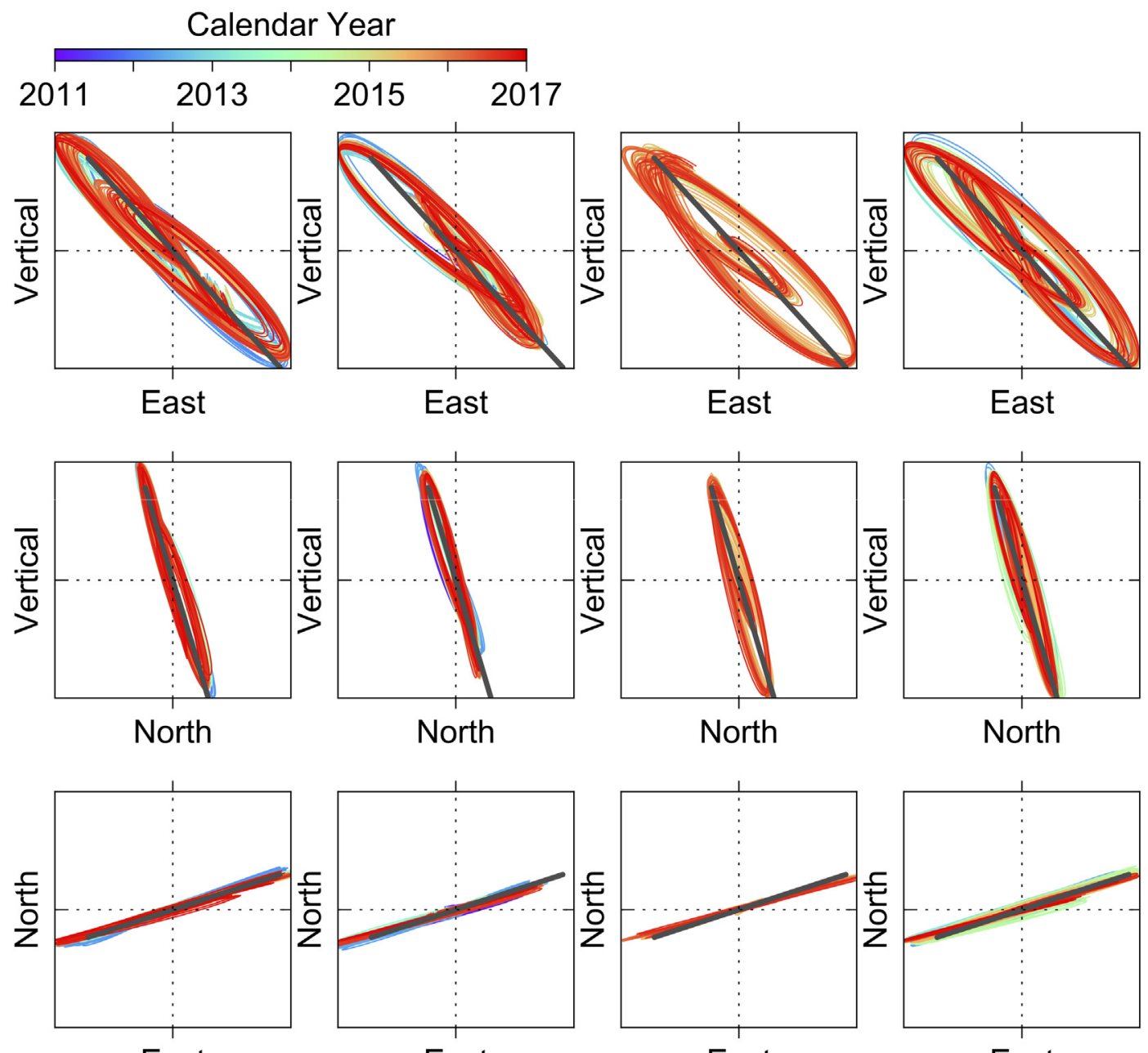

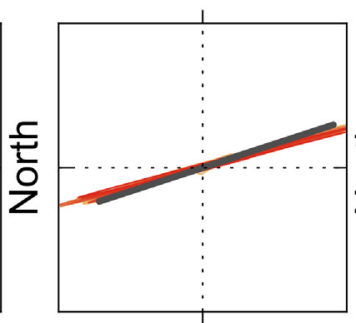

East

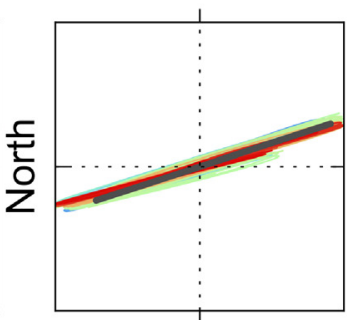

East

LPT-A

LPT-B

LPT-C

LPT-D

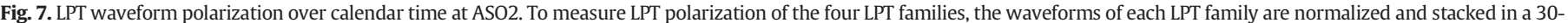

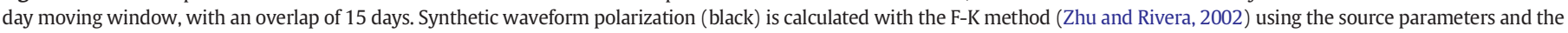

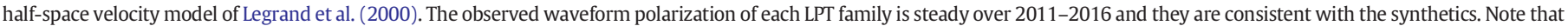
the polarization of waveform stacks with $<50$ events is considered less reliable and not included in the plot.

\subsection{Amplitude of diverse LPT family and changes in conduit overpressure}

As pointed out earlier, diverse LPT families display a notable and systematic change concerning surface volcanic activities. However, the amplitudes of these LPT families generally fluctuate rather consistently with a coherent trend (Fig. 8b), independent of the type of LPT family. Considering the geometry of the crack-like conduit remains largely constant, the amplitude of the tremors can be related to the overpressure (e.g., Aki et al., 1977; Chouet, 1985). As LPT source is predominantly associated with a volume and pressure change in the crack-like conduit (Kawakatsu et al., 2000), we suggest that LPT amplitude is dictated by a characteristic volume of hydrothermal fluid readily vaporized or outgassed inside the crack-like conduit, proportional to the change in overpressure.

\subsection{Activities of diverse LPT family and changes in conduit permeability/ strength}

One important aspect yet to address is the permeability of the conduit wall/plug, which presumably plays a major role in regulating the likelihood of pressurization and depressurization episodes. As demonstrated in cyclic loading/unloading experiments (e.g., Eberhardt et al., 1999; Vinciguerra et al., 2005; Heap et al., 2010; Benson et al., 2012), repeated pressurization/heating and depressurization/cooling associated with these LPT families likely extend pre-existing cracks or/ and promote the nucleation of new cracks, potentially consistent with more frequent LPT activities. Not only can these extended crack networks and new fractures increase the porosity and permeability of the wall rock and the conduit plug (e.g., Farquharson et al., 2016; Heap and Kennedy, 2016; Heap et al., 2017), but they also weaken their overall strength. Furthermore, repeated heating and cooling of rising gassed magma and cooling from the inflow of groundwater are also likely to occur in the well-documented hydrothermal system beneath the Naka-dake crater, introducing a higher degree of cracking (e.g., Burlini et al., 2007; Browning et al., 2016) and potentially leading to a reduction in the conduit wall/plug strength and stiffness (Heap et al., 2019; Mordensky et al., 2019).

To assess whether the conduit is prone to pressurization or depressurization and to infer the changes in conduit wall/plug permeability and their strength, we propose a simple attribute by contrasting the energetics of pressurization and depressurization events. We define the weekly moment as the product of the weekly number and median velocity to compute the weekly moment ratio (WMR) between LPT-A 
and LPT-B/C/D. Assuming that magma injection rate, conduit temperature, and overpressure are constant at a given week, we use the WMR as a proxy to infer changes in the permeability of the conduit wall/ plug. Since the WMR does not depend on LPT amplitude and the level of background noise, it is not biased by detection capability, providing a robust and uniform measure against episodes of LPT activities of different level (see also Fig. S7).

Typically, the WMR varies over 3 orders of magnitude ( 0.005-20) (Fig. 8c), with a high (low) WMR corresponding to the episodes prone to pressurization (depressurization). During phase 0 and phase 1 between 2011 and late 2014 (Fig. 8c), it stays mostly within 1-5, except the period of mid-2012 to mid-2013 where the WMR is relatively low at $0.1-1$. The WMR quickly decreases from $\sim 2$ to about 0.1 during phase $2 \mathrm{a}$ in late 2014 and typically varies between 0.1 and 0.5 during intermittent strombolian eruptions in early 2015 (Fig. 8c). The end of the Strombolian eruption in early 2015 marks the beginning of a sharp increase in WMR and it remains at a high level of $\sim 2$ during phase 1 in mid-2015. The WMR again decreases sharply from 2 to about 0.1 or lower in phase $2 \mathrm{a}$ in mid-late 2015 , continuously fluctuating at a low level of $\sim 0.1-0.3$ during phase $2 \mathrm{~b}$ until mid-2016. In late 2016, the WMR again increases to a relatively high level of about 1 in phase 1 , followed by a lower WMR in phase 2b before the 2016 phreatomagmatic explosion.

We suggest that, depending on the strength of the surrounding rock and the permeability of the crack-like conduit wall/plug, pressurization (e.g., LPT-A family) due to magmatic heat and vaporization is more likely to occur when a strong or/and less permeable conduit plug/wall can effectively keep the gas inside the crack-like conduit (e.g., Heap

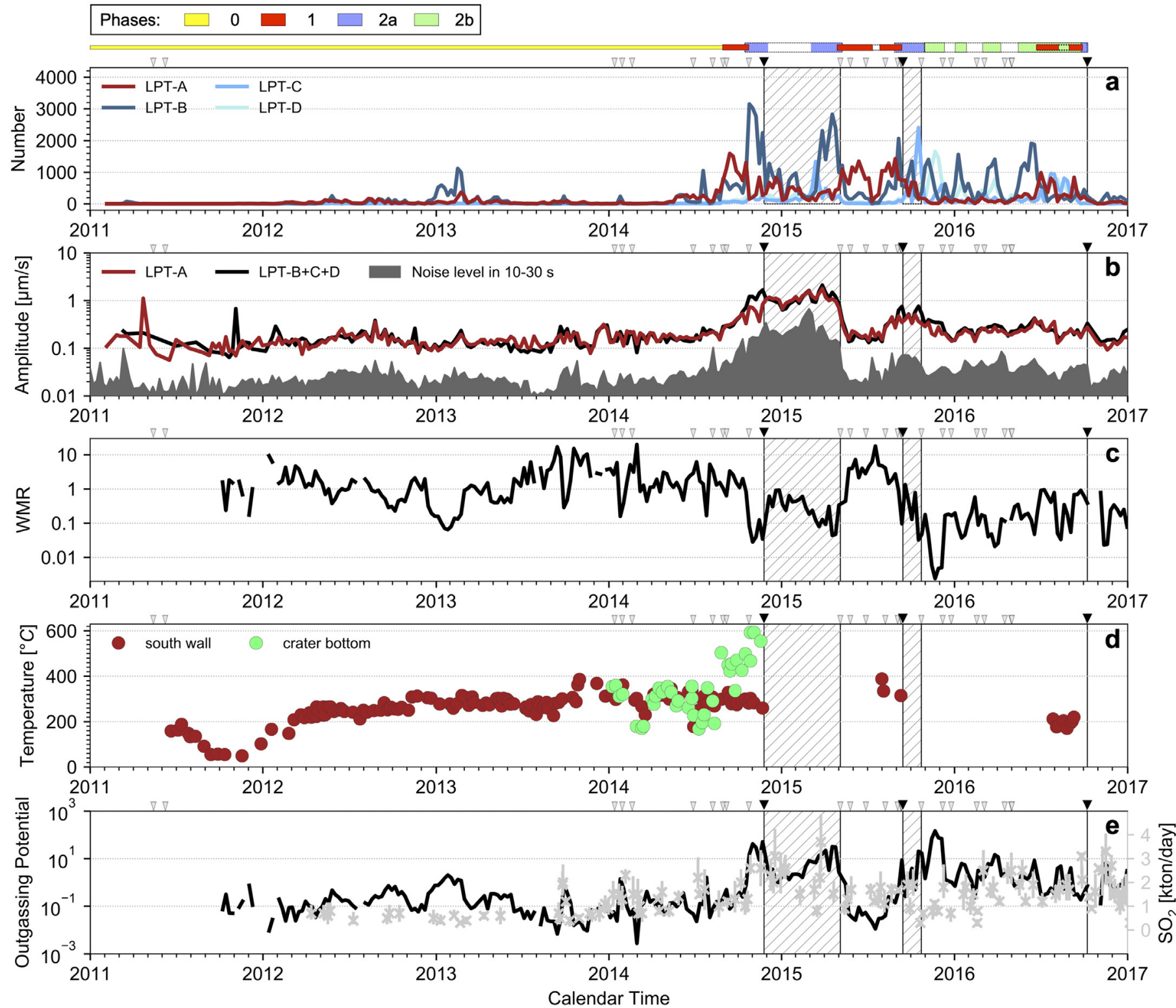

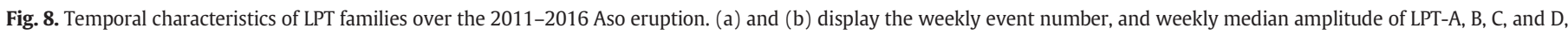

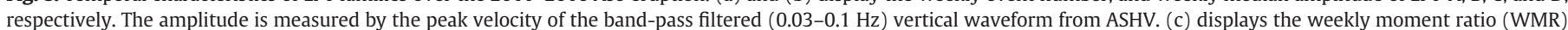

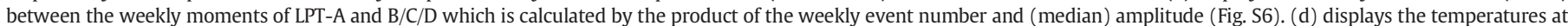

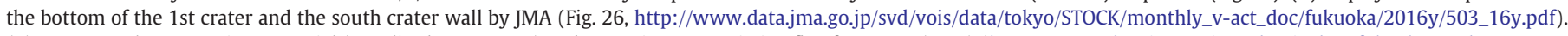

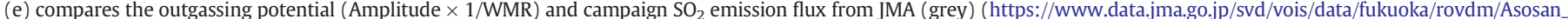

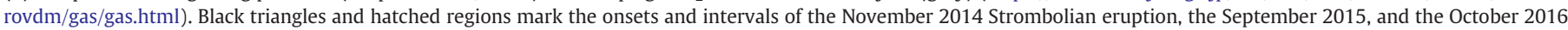

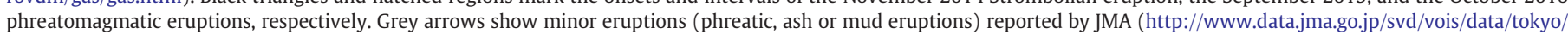
STOCK/monthly_v-act_doc/monthly_vact_vol.php?id=503) and the Global Volcanism Program $(2011,2012,2015,2017)$. 
and Wadsworth, 2016). On the other hand, depressurization (e.g., LPT$\mathrm{B} / \mathrm{C} / \mathrm{D}$ families) is prone to occur if the conduit wall/plug permeability is sufficiently high to allow gas to escape from the conduit. In the meantime, if the overpressure, at least locally, overcomes the strength of the caprock or/and the conduit wall, additional cracks can form, and the gas can escape toward the crater bottom of the edifice. Nevertheless, by contrasting the level of activity between LPT-A family and LPT-B/C/D families, or equivalently the tendency of pressurization events against the depressurization events, we may infer the changes in the balance between the overpressure and the permeability/strength of the conduit wall/plug.

\subsection{A new observational framework and inferences of overpressure and conduit wall permeability/strength}

While experimental data and theoretical considerations have shown that pore pressure can effectively modulate permeability (Zoback and Byerlee, 1975; Walsh, 1981; Berryman, 1992; Paterson and Wong, 2005; Nara et al., 2011), nonlinear feedback or two-way coupling between permeability and overpressure is often not included in the numerical simulation (e.g., Diller et al., 2006; Girona et al., 2019). Therefore, it is the motivation of this paper to present relevant observational attributes that can be used to directly infer overpressure (LPT amplitude), permeability (WMR), and how they may evolve at different stages of volcanic activities. As discussed in the following, the activities of diverse LPT and a simple attribute of WMR offer a new framework to evaluate the interplay and feedback among conduit overpressure and conduit plug/wall permeability and rheology (Fig. 9).

With a low LPT amplitude and a weak activity (e.g., phase 0), we suggest the strength of the conduit wall/plug is generally strong and less permeable when the WMR is high, making the gas less likely to escape at this stage. The conduit overpressure is relatively low, subjected to steady but episodic magmatic heating. On the other hand, with a high LPT amplitude, a strong activity, and a high WMR (e.g., phase 1), the conduit wall/plug remains sufficiently strong, potentially subjected to elevated magmatic heating and overpressure. With a high LPT amplitude, a strong activity, but a low WMR (e.g., phase 2a), the strength of the conduit wall/plug is significantly reduced due to more extended cracks, allowing the gas to escape more effectively and frequently. Presumably, magmatic injection or heating from the deep conduit or/and chamber remains at a high level and the conduit is still under a relatively high overpressure. We consider that this is the stage where the overpressure is high and the mechanical strength of the conduit plug/wall is low due to enhanced permeability (stress-dependent), leading to the failure and an imminent eruption. Finally, with a relatively low LPT amplitude, an elevated activity, and a low WMR (e.g., phase 2b), the conduit wall/plug with extended fractures remains weak and more permeable as the conduit overpressure decreases, possibly subjected to relatively weak magmatic heating.

As summarized in Fig. 9, we suggest that the 2011-2016 Aso eruption cycle likely begins with a strong or/and less permeable conduit plug/wall under a relatively low overpressure. The Strombolian eruption in late 2014 and the subsequent phreatomagmatic eruptions in late 2015 and late 2016 are preceded by an early episode of a comparatively strong or/and less permeable conduit wall/plug and an increasing overpressure (prone to pressurization). After an increase of overpressure over days/months, the conduit wall/plug subjected to a high overpressure becomes weaker or/and more permeable, allowing efficient gas to escape (prone to depressurization) and leading to the upcoming major eruptions. Several minor eruptions in the late stage of the eruption cycle in 2016 are also preceded by the episodes of weak or/and more permeable conduit wall/plug, responding to the episodic depressurization and pressurization under relatively low overpressure (Figs. 8, 9).
5.5. Diverse LPT activities vs. surface volcanic activities, eruption style, and $\mathrm{SO}_{2}$ emission?

We find that the WMR also corresponds to surface volcanic activities systematically, indicative of whether the upcoming eruption is of the magmatic or hydrothermal origin (dominated by gas). As discussed earlier in Section 4.3 and 5, the extended period of phase 1 or high WMR $(\sim 1)$ are typically the prologues of magmatic eruptions in 2014, 2015, and 2016, which involve juvenile magma. It is consistent with magma rising from the crack-like conduit toward the crater bottom, evidenced by the episode of prominent temperature increase (Fig. 8d). On the other hand, phase 2a typically corresponds to the stages of rapid decline in the WMR $(\sim 0.01-0.1)$, suggesting a more substantial gas escape from the crack-like conduit toward the crater bottom, resulting in a rapid buildup of gas near the crater bottom before the imminent eruption.

As discussed in the above section, the amplitude of VLP or tremor in other volcanoes has been correlated with $\mathrm{SO}_{2}$ emission flux (e.g., Kazahaya et al., 2011; Nadeau et al., 2011; Waite et al., 2013; Zuccarello et al., 2013). However, among other geometric factors (e.g., cross-section area, characteristic length scale), $\mathrm{SO}_{2}$ emission is presumably modulated by pressure drop as well as permeability (e.g., Edmonds et al., 2003). In most instances, syn-eruptive VLPs or tremors only allow such a comparison during eruptions, whereas repetitive LPT in Aso volcano provides an excellent opportunity to systematically compare $\mathrm{SO}_{2}$ emission flux against LPT activity throughout the entire eruption cycle in 2011-2016. Here we define the outgassing potential as the product of LPT amplitude (a proxy of pressure drop) and WMR (a proxy of permeability) and compare it against campaign $\mathrm{SO}_{2}$ emission data (JMA) in the 2011-2016 eruption cycle (Figs. 8e, S5e). We find that the outgassing potential correlates satisfactorily well with the $\mathrm{SO}_{2}$ emission data, especially during the unrest and active period between late 2013 and 2016. This result also implies that geometric factors remain either approximately constant or they are inherently included in WMR or permeability, which is geometry dependent. It is conceivable that joint modeling of outgassing potential, high-frequency tremors (e.g., Ichimura et al., 2018; Takagi et al., 2006, 2009) and LP (e.g., Mori et al., 2008) near the upper end of the crack-like conduit, as well as continuous $\mathrm{SO}_{2}$ emission data can shed light on the evolution of the shallow conduit system and the eruption potential in a persistent degassing volcano such as Aso.

\subsection{Outlook and future work}

In this report, we have detected diverse LPT families during the 2011-2016 eruption cycle at Aso volcano in Japan. Systematics of their activities, as discussed above, offer a new perspective and insight into the interplay and feedback among key components regulating the style and timing of upcoming eruptions. The hydrothermal system beneath the Aso crater has been fruitfully discussed in the literature (e.g., Tanaka, 1993; Hase et al., 2005; Terada et al., 2012; Shinohara, 2013; Hata et al., 2016, 2018; Minami et al., 2018; Kanda et al., 2019). If the polarities of these LPT families can be associated with pressurization and depressurization (e.g., Kaneshima et al., 1996; Kawakatsu et al., 2000; Legrand et al., 2000), measurements of the amplitude, frequency of LPT as well as the WMR in real-time provide very useful attributes to monitor the evolution of conduit permeability/strength and pressure in situ. In particular, as the physical properties of the fluid (e.g., gas, vapor, magma, etc.) or/and the elasticity of the conduit plug/wall will probably change the attenuation, excitation period and modal interference of LPT (e.g., Kumagai and Chouet, 2000, 2001; Chouet et al., 2003; Namiki et al., 2018). Systematically analyzing the spectral characteristics of these LPT families over time potentially provides a further constraint on the temporal evolution of fluid properties and conduit plug/wall rheology over the eruption cycle (Niu and Song, in preparation).

One of the outstanding questions we did not address is the triggering mechanism of these diverse LPT families. While we have associated 

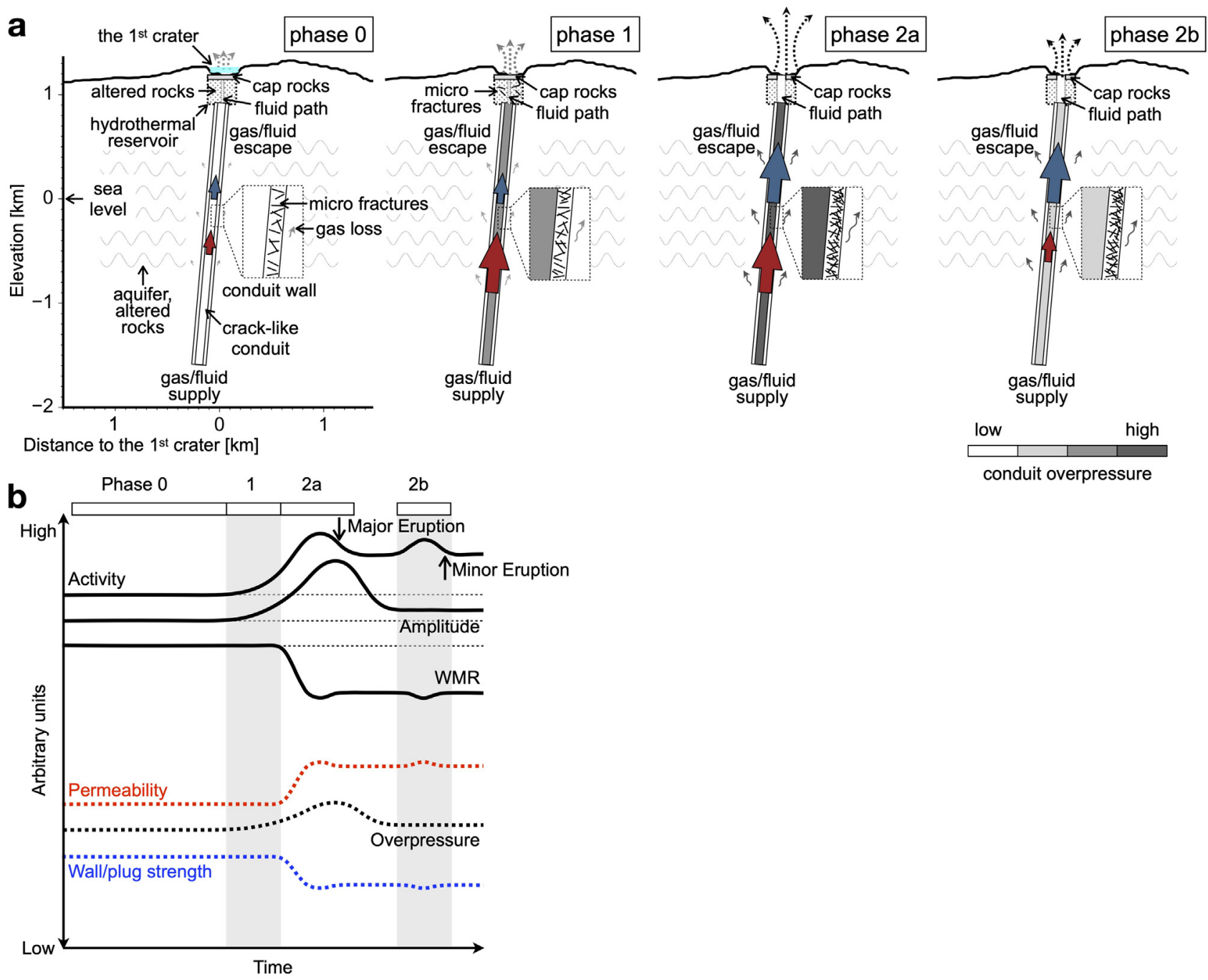

conduit overpressure

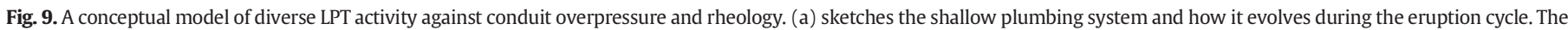

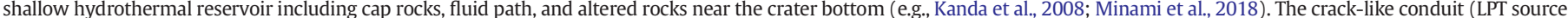

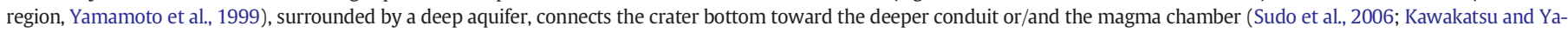

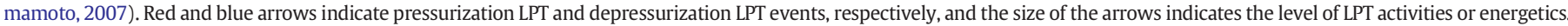

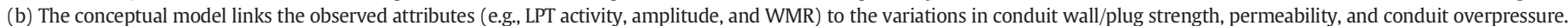

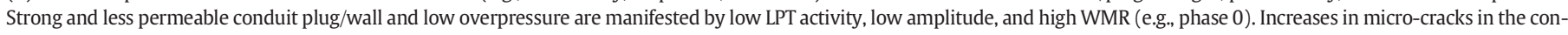

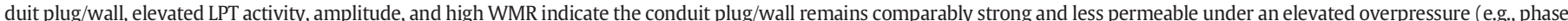

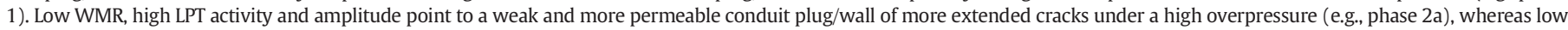
WMR, low amplitude, and high LPT activity reflect a weak conduit plug/wall under a low overpressure (e.g., phase $2 \mathrm{~b}$ ).

diverse LPT families with outgassing, the supply of gassed magma, and vaporization, it is not entirely clear if the outgassing process or upward transport of gassed magma and vaporization directly trigger LPT. It is conceivable that these processes may simply respond to an unknown source $(s)$. As discussed earlier, the amplitude of LPT does not depend on the type of LPT family, which could be consistent with the latter scenario. Furthermore, it is not clear if the triggering source is necessarily collocated or spatially separated from the LPT source. Is the LPT activity related to the occurrence of deep low-frequency earthquakes at advocated in some volcanoes (e.g., Shapiro et al., 2017), or does the triggering manifest as a seismic source that is currently unknown? These outstanding issues will be explored in future work. Nevertheless, detailed waveform analysis may be performed against historical eruptions in Aso and similar efforts can potentially be extended to other volcanoes where VLP (or LP) is identified. Temporal seismic velocity changes may be measured to infer variations in the strength of conduit wall rock (e.g., Nara et al., 2011). When near-field seismic observations are not available, far-field observations of Rayleigh waves can potentially help provide continuous monitoring (e.g., Hashida, 1990; Kawakatsu et al., 1994; Sandanbata et al., 2015).

\section{CRediT authorship contribution statement}

Jieming Niu: Conceptualization, Methodology, Software, Validation, Formal analysis, Investigation, Resources, Data curation, Writing - original draft, Visualization. Teh-Ru Alex Song: Methodology, Validation, Formal analysis, Writing - review \& editing, Supervision, Project administration, Funding acquisition, Conceptualization.

\section{Declaration of competing interest}

The authors declare that they have no known competing financial interests or personal relationships that could have appeared to influence the work reported in this paper. 


\section{Acknowledgments}

J. Niu acknowledges the support by Prof. Caijun Xu and the China Scholarship Council to make the research visit at UCL possible. We gratefully thank NIED and JMA providing us the high-quality waveform data of V-net. We are also grateful to Prof. Mare Yamamoto and Prof. Takuhiro Ohkura for hosting J. Niu in Aso Volcanic Observatory and Tohoku University during the early stage of this work, which help improve our understanding of LPT and Aso volcanic system. The uses of the UCL Legion High-Performance Computing Facility (Legion@UCL), the UCL Grace High-Performance Computing Facility (Grace@UCL), the UCL Emerald High-Performance Computing Facility (Emerald@UCL) and associated support services are acknowledged. Data processing and production of figures are implemented in Python with relevant modules such as ObsPy and PyCUDA. J. Niu and T.-R. A. Song are supported by the Natural Environment Research Council, UK (NE/ P001378/1 \& NE/T001372/1). We thank the editor Diana Roman for handling the manuscript and two anonymous reviewers for their comments, which help clarify and improve this paper.

\section{Appendix A. Supplementary data}

Supplementary data to this article can be found online at https://doi. org/10.1016/j.jvolgeores.2020.106964.

\section{References}

Abe, Y., Ohkura, T., Shibutani, T., Hirahara, K., Kato, M., 2010. Crustal structure beneath Aso Caldera, Southwest Japan, as derived from receiver function analysis. J. Volcanol. Geotherm. Res. 195 (1), 1-12. https://doi.org/10.1016/j.jvolgeores.2010.05.011.

Abe, Y., Ohkura, T., Shibutani, T., Hirahara, K., Yoshikawa, S., Inoue, H., 2017. Low-velocity zones in the crust beneath Aso caldera, Kyushu, Japan, derived from receiver function analyses: Low-velocity zones beneath Aso caldera. Journal of Geophysical Research: Solid Earth https://doi.org/10.1002/2016JB013686.

Aki, K., Fehler, M., Das, S., 1977. Source mechanism of volcanic tremor: fluid-driven crack models and their application to the 1963 Kilauea eruption. J. Volcanol. Geotherm. Res. 2 (3), 259-287. https://doi.org/10.1016/0377-0273(77)90003-8.

Arciniega-Ceballos, A., Chouet, B.A., Dawson, P., 1999. Very long-period signals associated with Vulcanian explosions at Popocatepetl volcano, Mexico. Geophys. Res. Lett. 26 (19), 3013-3016. https://doi.org/10.1029/1999GL005390.

Arciniega-Ceballos, A., Chouet, B., Dawson, P., Asch, G., 2008. Broadband seismic measurements of degassing activity associated with lava effusion at Popocatépetl volcano Mexico. J. Volcanol. Geotherm. Res. 170 (1-2), 12-23. https://doi.org/10.1016/j. jvolgeores.2007.09.007.

Aster, R., Mah, S., Kyle, P., Mclntosh, W., Dunbar, N., Johnson, J., et al., 2003. Very long period oscillations of Mount Erebus volcano. J. Geophys. Res. 108 (B11), 2522. https:// doi.org/10.1029/2002JB002101.

Aster, R., Zandomeneghi, D., Mah, S., McNamara, S., Henderson, D.B., Knox, H., Jones, K. 2008. Moment tensor inversion of very long period seismic signals from Strombolian eruptions of Erebus volcano. J. Volcanol. Geotherm. Res. 177 (3), 635-647. https://doi. org/10.1016/j.jvolgeores.2008.08.013.

Bain, A.A., Lamur, A., Kendrick, J.E., Lavallée, Y., Calder, E.S., Cortés, J.A., et al., 2019. Constraints on the porosity, permeability and porous micro-structure of highlycrystalline andesitic magma during plug formation. J. Volcanol. Geotherm. Res. 379, 72-89. https://doi.org/10.1016/j.jvolgeores.2019.05.001.

Bean, C.J., Lokmer, I., O'Brien, G., 2008. Influence of near-surface volcanic structure on long-period seismic signals and on moment tensor inversions: simulated examples from Mount Etna: volcanic structure influence on LPs. Journal of Geophysical Research: Solid Earth 113 (B8). https://doi.org/10.1029/2007JB005468.

Bean, C.J., De Barros, L., Lokmer, I., Métaxian, J.-P., O’ Brien, G., Murphy, S., 2014. Longperiod seismicity in the shallow volcanic edifice formed from slow-rupture earthquakes. Nat. Geosci. 7 (1), 71-75. https://doi.org/10.1038/ngeo2027.

Benson, P.M., Heap, M.J., Lavallée, Y., Flaws, A., Hess, K.-U., Selvadurai, A.P.S., et al., 2012. Laboratory simulations of tensile fracture development in a volcanic conduit via cyclic magma pressurisation. Earth Planet. Sci. Lett. 349-350, 231-239, https://doi. org/10.1016/j.epsl.2012.07.003.

Berryman, J.G., 1992. Effective stress for transport properties of inhomogeneous porous rock. J. Geophys. Res. 97 (B12), 17409. https://doi.org/10.1029/92JB01593.

Browning, J., Meredith, P., Gudmundsson, A., 2016. Cooling-dominated cracking in thermally stressed volcanic rocks. Geophys. Res. Lett. 43 (16), 8417-8425. https://doi. org/10.1002/2016GL070532.

Burlini, L., Vinciguerra, S., Di Toro, G., De Natale, G., Meredith, P., Burg, J.-P., 2007. Seismicity preceding volcanic eruptions: new experimental insights. Geology 35 (2), 183 https://doi.org/10.1130/G23195A.1.

Burton, M.R., Mader, H.M., Polacci, M., 2007. The role of gas percolation in quiescent degassing of persistently active basaltic volcanoes. Earth Planet. Sci. Lett. 264 (1-2), 46-60. https://doi.org/10.1016/j.epsl.2007.08.028.
Cashman, K.V., Sparks, R.S.J., Blundy, J.D., 2017. Vertically extensive and unstable magmatic systems: a unified view of igneous processes. Science 355 (6331). https://doi. org/10.1126/science.aag3055 eaag 3055.

Chouet, B., 1985. Excitation of a buried magmatic pipe: a seismic source model for volcanic tremor. J. Geophys. Res. 90 (B2), 1881. https://doi.org/10.1029/JB090iB02p01881.

Chouet, B.A., 1996. Long-period volcano seismicity: its source and use in eruption forecasting. Nature 380 (6572), 309-316. https://doi.org/10.1038/380309a0.

Chouet, B., 2003. Volcano seismology. Pure Appl. Geophys. 160 (3), 739-788. https://doi. org/10.1007/PL00012556.

Chouet, B.A., 2009. Volcanoes, non-linear processes in. Encyclopedia of Complexity and Systems Science. Springer-Verlag New York, pp. 9872-9899.

Chouet, B.A., Matoza, R.S., 2013. A multi-decadal view of seismic methods for detecting precursors of magma movement and eruption. J. Volcanol. Geotherm. Res. 252, 108-175. https://doi.org/10.1016/j.jvolgeores.2012.11.013.

Chouet, B.A., Page, R.A., Stephens, C.D., Lahr, J.C., Power, J.A., 1994. Precursory swarms of long-period events at Redoubt Volcano (1989-1990), Alaska: their origin and use as a forecasting tool. J. Volcanol. Geotherm. Res. 62 (1-4), 95-135. https://doi.org/ 10.1016/0377-0273(94)90030-2.

Chouet, B., Dawson, P., Ohminato, T., Martini, M., Saccorotti, G., Giudicepietro, F., et al., 2003. Source mechanisms of explosions at Stromboli volcano, Italy, determined from moment-tensor inversions of very-long-period data: source mechanisms of explosion at Stromboli source. Journal of Geophysical Research: Solid Earth 108 (B1). https://doi.org/10.1029/2002JB001919 ESE 7-1-ESE 7-25.

Churei, M., 1985. Particle motion properties and amplitudefrequency distributions of volcanic long-period tremors of Aso volcano, Kyushu (in Japanese). Bulletin of the Volcanological Society of Japan 30, 71-80.

Collinson, A.S.D., Neuberg, J.W., 2012. Gas storage, transport and pressure changes in an evolving permeable volcanic edifice. J. Volcanol. Geotherm. Res. 243-244, 1-13. https://doi.org/10.1016/j.jvolgeores.2012.06.027.

Davis, P. Ishii, M., Masters, G., 2005. An assessment of the accuracy of GSN sensor response information. Seismol. Res. Lett. 76 (6), 678-683. https://doi.org/10.1785/ gssrl.76.6.678.

Dawson, P., Chouet, B., 2014. Characterization of very-long-period seismicity accompanying summit activity at Kīlauea Volcano, Hawai'i: 2007-2013. J. Volcanol. Geotherm. Res. 278-279, 59-85. https://doi.org/10.1016/j.jvolgeores.2014.04.010.

Dawson, P.B., Dietel, C., Chouet, B.A., Honma, K., Ohminato, T., Okubo, P., 1998. Digitally Telemetered Broadband Seismic Network at Kilauea Volcano, Hawaii (Open-File Report).

Dawson, P.B., Chouet, B.A., Power, J., 2011. Determining the seismic source mechanism and location for an explosive eruption with limited observational data: Augustine Volcano, Alaska: eruption mechanism at Augustine. Geophys. Res. Lett. 38 (3), L03302. https://doi.org/10.1029/2010GL045977.

Diller, K., Clarke, A.B., Voight, B., Neri, A., 2006. Mechanisms of conduit plug formation: Implications for vulcanian explosions. Geophys. Res. Lett. 33 (20), L20302. https:// doi.org/10.1029/2006GL027391.

Eberhardt, E., Stead, D., Stimpson, B., 1999. Quantifying progressive pre-peak brittle fracture damage in rock during uniaxial compression. Int. J. Rock Mech. Min. Sci. 36 (3), 361-380. https://doi.org/10.1016/S0148-9062(99)00019-4.

Edmonds, Marie, Herd, R.A., 2007. A volcanic degassing event at the explosive-effusive transition. Geophys. Res. Lett. 34 (21), L21310. https://doi.org/10.1029/ 2007GL031379.

Edmonds, M., Herd, R.A., Galle, B., Oppenheimer, C.M., 2003. Automated, high timeresolution measurements of SO2 flux at Soufriére Hills Volcano, Montserrat. Bull. Volcanol. 65 (8), 578-586. https://doi.org/10.1007/s00445-003-0286-X.

Ekstrom, G., Dalton, C.A., Nettles, M., 2006. Observations of time-dependent errors in long-period instrument gain at global seismic stations. Seismol. Res. Lett. 77 (1), 12-22. https://doi.org/10.1785/gssrl.77.1.12.

Farquharson, J., Heap, M.J., Baud, P., Reuschlé, T., Varley, N.R., 2016. Pore pressure embrittlement in a volcanic edifice. Bull. Volcanol. 78 (1), 6. https://doi.org/10.1007/ s00445-015-0997-9.

Farquharson, J.I., Wild, B., Kushnir, A.R.L., Heap, M.J., Baud, P., Kennedy, B., 2019. Acidinduced dissolution of andesite: evolution of permeability and strength. Journal of Geophysical Research: Solid Earth 124 (1), 257-273. https://doi.org/10.1029/ 2018JB016130.

Fernández, J., Pepe, A., Poland, M.P., Sigmundsson, F., 2017. Volcano geodesy: recent developments and future challenges. J. Volcanol. Geotherm. Res. 344, 1-12. https:// doi.org/10.1016/j.jvolgeores.2017.08.006.

Gaunt, H.E., Sammonds, P.R., Meredith, P.G., Chadderton, A., 2016. Effect of temperature on the permeability of lava dome rocks from the 2004-2008 eruption of Mount St. Helens. Bulletin of Volcanology 78 (4), 30. https://doi.org/10.1007/s00445-0161024-5.

Girona, T., Caudron, C., Huber, C., 2019. Origin of shallow volcanic tremor: the dynamics of gas pockets trapped beneath thin permeable media. Journal of Geophysical Research: Solid Earth 124 (5), 4831-4861. https://doi.org/10.1029/2019JB017482.

Global Volcanism Program, 2011. Report on Asosan (Japan). Bulletin of the Global Volcanism Network 36 (9). https://doi.org/10.5479/si.GVP.BGVN201109-282110.

Global Volcanism Program, 2012. Report on Asosan (Japan). Bulletin of the Global Volcanism Network 37 (8). https://doi.org/10.5479/si.GVP.BGVN201208-282110.

Global Volcanism Program, 2015. Report on Asosan (Japan). Bulletin of the Global Volcanism Network 40 (2). https://doi.org/10.5479/si.GVP.BGVN201502-282110.

Global Volcanism Program, 2017. Report on Asosan (Japan). Bulletin of the Global Volcanism Network 42 (5). https://doi.org/10.5479/si.GVP.BGVN201705-282110.

Gonnermann, H.M., Manga, M., 2003. Explosive volcanism may not be an inevitable consequence of magma fragmentation. Nature 426 (6965), 432-435. https://doi.org/ 10.1038 /nature02138. 
Gonnermann, H.M., Giachetti, T., Fliedner, C., Nguyen, C.T., Houghton, B.F., Crozier, J.A., Carey, R.J., 2017. Permeability during magma expansion and compaction: expansion-compaction permeability. J. Geophys. Res. Solid Earth 122 (12), 9825-9848. https://doi.org/10.1002/2017JB014783.

Grossmann, A., Morlet, J., 1984. Decomposition of Hardy functions into square integrable wavelets of constant shape. SIAM J. Math. Anal. 15 (4), 723-736. https://doi.org/ $10.1137 / 0515056$.

Hammer, C., Neuberg, J.W., 2009. On the dynamical behaviour of low-frequency earthquake swarms prior to a dome collapse of Soufrière Hill volcano, Montserrat. Geophys. Res. Lett. 36 (6), L06305. https://doi.org/10.1029/2008GL036837.

Haney, M.M., 2010. Location and mechanism of very long period tremor during the 2008 eruption of Okmok Volcano from interstation arrival times. J. Geophys. Res. 115, B00B05. https://doi.org/10.1029/2010JB007440.

Haney, M.M., Chouet, B.A., Dawson, P.B., Power, J.A., 2013. Source characterization for an explosion during the 2009 eruption of Redoubt volcano from very-long-period seismic waves. J. Volcanol. Geotherm. Res. 259, 77-88. https://doi.org/10.1016/j. jvolgeores.2012.04.018.

Hase, H., Hashimoto, T., Sakanaka, S., Kanda, W., Tanaka, Y., 2005. Hydrothermal system beneath Aso volcano as inferred from self-potential mapping and resistivity structure. J. Volcanol. Geotherm. Res. 143 (4), 259-277. https://doi.org/10.1016/j. jvolgeores.2004.12.005

Hashida, T., 1990. Long-period micro-tremors observed in the Kyushu district, as excited by 1989 volcanic activity of the Aso Naka-dake. Bulletin of the Volcanological Society of Japan 35, 323-326.

Hata, M., Takakura, S., Matsushima, N., Hashimoto, T., Utsugi, M., 2016. Crustal magma pathway beneath Aso caldera inferred from three-dimensional electrical resistivity structure: Crustal magma pathway in Aso caldera. Geophys. Res. Lett. 43 (20), 10,720-10,727. https://doi.org/10.1002/2016GL070315.

Hata, M., Uyeshima, M., Tanaka, Y., Hashimoto, T., Oshiman, N., Yoshimura, R., 2018. Three-dimensional electrical resistivity distribution beneath the Beppu-Shimabara graben with a focus on Aso caldera, Southwest Japan subduction zone. Journal of Geophysical Research: Solid Earth https://doi.org/10.1029/2018JB015506.

Heap, M.J., Kennedy, B.M., 2016. Exploring the scale-dependent permeability of fractured andesite. Earth Planet. Sci. Lett. 447, 139-150. https://doi.org/10.1016/j. epsl.2016.05.004.

Heap, M.J., Wadsworth, F.B., 2016. Closing an open system: pore pressure changes in permeable edifice rock at high strain rates. J. Volcanol. Geotherm. Res. 315, 40-50. https://doi.org/10.1016/j.jvolgeores.2016.02.011.

Heap, M.J., Faulkner, D.R., Meredith, P.G., Vinciguerra, S., 2010. Elastic moduli evolution and accompanying stress changes with increasing crack damage: implications for stress changes around fault zones and volcanoes during deformation: elastic moduli evolution and stress changes. Geophys. J. Int. 183 (1), 225-236. https://doi.org/ 10.1111/j.1365-246X.2010.04726.x.

Heap, M.J., Farquharson, J.I., Baud, P., Lavallée, Y., Reuschlé, T., 2015. Fracture and compaction of andesite in a volcanic edifice. Bull. Volcanol. 77 (6), 55. https://doi.org/ 10.1007/s00445-015-0938-7.

Heap, M.J., Violay, M., Wadsworth, F.B., Vasseur, J., 2017. From rock to magma and back again: the evolution of temperature and deformation mechanism in conduit margin zones. Earth Planet. Sci. Lett. 463, 92-100. https://doi.org/10.1016/j.epsl.2017.01.021.

Heap, M.J., Reuschlé, T., Farquharson, J.I., Baud, P., 2018a. Permeability of volcanic rocks to gas and water. J. Volcanol. Geotherm. Res. 354, 29-38. https://doi.org/10.1016/j. jvolgeores.2018.02.002

Heap, M.J., Coats, R., Chen, C., Varley, N., Lavallée, Y., Kendrick, J., et al., 2018b. Thermal resilience of micro cracked andesitic dome rocks. J. Volcanol. Geotherm. Res. 367, 20-30. https://doi.org/10.1016/j.jvolgeores.2018.10.021.

Heap, M.J., Troll, V.R., Kushnir, A.R.L., Gilg, H.A., Collinson, A.S.D., Deegan, F.M., et al., 2019. Hydrothermal alteration of andesitic lava domes can lead to explosive volcanic behaviour. Nat. Commun. 10 (1), 5063. https://doi.org/10.1038/s41467-019-13102-8.

Heiken, G., Wohletz, K., Eichelberger, J., 1988. Fracture fillings and intrusive pyroclasts, Inyo Domes, California. Journal of Geophysical Research: Solid Earth 93 (B5), 4335-4350. https://doi.org/10.1029/JB093iB05p04335.

Hendriyana, A., Tsuji, T., 2019. Migration of very long period seismicity at Aso Volcano, Japan, associated with the 2016 Kumamoto Earthquake. Geophys. Res. Lett. 46 (15), 8763-8771. https://doi.org/10.1029/2019GL082645.

Hidayat, D., Voight, B., Langston, C., Ratdomopurbo, A., Ebeling, C., 2000. Broadband seismic experiment at Merapi Volcano, Java, Indonesia: very-long-period pulses embedded in multiphase earthquakes. J. Volcanol. Geotherm. Res. 100 (1-4), 215-231. https://doi.org/10.1016/S0377-0273(00)00138-4.

Hill, D.P., Dawson, P., Johnston, M.J.S., Pitt, A.M., Biasi, G., Smith, K., 2002. Very-long-period volcanic earthquakes beneath Mammoth Mountain, California: VLP volcanic earthquakes. Geophys. Res. Lett. 29 (10). https://doi.org/10.1029/2002GL014833 8-1-8-4

Huang, Y.C., Ohkura, T., Kagiyama, T., Yoshikawa, S., Inoue, H., 2018. Shallow volcanic reservoirs and pathways beneath Aso caldera revealed using ambient seismic noise tomography. Earth Planets Space 70 (1), 169. https://doi.org/10.1186/s40623-0180941-2.

Hunter, A.G., 1998. Intracrustal controls on the coexistence of tholeiitic and calc-alkaline magma series at Aso volcano, SW Japan. J. Petrol. 39 (7), 1255-1284. https://doi.org/ 10.1093/petroj/39.7.1255.

Ichimura, M., Yokoo, A., Kagiyama, T., Yoshikawa, S., Inoue, H., 2018. Temporal variation in source location of continuous tremors before ash-gas emissions in January 2014 at Aso volcano, Japan. Earth Planets Space 70, 125. https://doi.org/10.1186/s40623018-0895-4.

Ikebe, S., Watanabe, K., Miyabuchi, Y., 2008. The sequence and style of the 1988-1995 eruptions of Nakadake Aso volcano, Kyushu, Japan (in Japanese). Bulletin of the Volcanological Society of Japan 53, 15-33.
Ikeda, S., 2005. Temporal Change of Long-period Tremor at Aso Volcano -2002-2004-. (Master Thesis). Tokyo University, Tokyo.

Ishibashi, H., Suwa, Y., Miyoshi, M., Yasuda, A., Hokanishi, N., 2018. Amphibole-melt disequilibrium in silicic melt of the Aso- 4 caldera-forming eruption at Aso volcano, SW Japan. Earth, Planets and Space 70 (1), 137. https://doi.org/10.1186/s40623-0180907-4.

Ishii, K., 2018. Estimation of emission mass from an eruption plume for the Aso volcano eruption, on October 8, 2016, using a four-dimensional variational method. Earth, Planets and Space 70 (1), 202. https://doi.org/10.1186/s40623-018-0964-8.

Ishii, K., Hayashi, Y., Shimbori, T., 2018. Using Himawari-8, estimation of SO2 cloud altitude at Aso volcano eruption, on October 8, 2016. Earth, Planets and Space 70 (1), 19. https://doi.org/10.1186/s40623-018-0793-9.

Jaupart, C., 1998. Gas loss from magmas through conduit walls during eruption. Geol. Soc. Lond., Spec. Publ. 145 (1), 73-90. https://doi.org/10.1144/GSL.SP.1996.145.01.05.

Jaupart, C., Allègre, C.J., 1991. Gas content, eruption rate and instabilities of eruption regime in silicic volcanoes. Earth Planet. Sci. Lett. 102 (3-4), 413-429. https://doi.org/ 10.1016/0012-821X(91)90032-D.

Jolly, A.D., Lokmer, I., Thun, J., Salichon, J., Fry, B., Chardot, L., 2017. Insights into fluid transport mechanisms at White Island from analysis of coupled very long-period (VLP), long-period (LP) and high-frequency (HF) earthquakes. J. Volcanol. Geotherm. Res. 343, 75-94. https://doi.org/10.1016/j.jvolgeores.2017.06.006.

Jolly, A., Lokmer, I., Christenson, B., Thun, J., 2018. Relating gas ascent to eruption triggering for the April 27, 2016, White Island (Whakaari), New Zealand eruption sequence. Earth, Planets and Space 70 (1), 177. https://doi.org/10.1186/s40623-018-0948-8.

Kanda, W., Tanaka, Y., Utsugi, M., Takakura, S., Hashimoto, T., Inoue, H., 2008. A preparation zone for volcanic explosions beneath Naka-dake crater, Aso volcano, as inferred from magnetotelluric surveys. J. Volcanol. Geotherm. Res. 178 (1), 32-45. https://doi. org/10.1016/j.jvolgeores.2008.01.022.

Kanda, W., Utsugi, M., Takakura, S., Inoue, H., 2019. Hydrothermal system of the active crater of Aso volcano (Japan) inferred from a three-dimensional resistivity structure model. Earth, Planets and Space 71 (1), 37. https://doi.org/10.1186/s40623-0191017-7.

Kaneko, K., Kamata, H., Koyaguchi, T., Yoshikawa, M., Furukawa, K., 2007. Repeated largescale eruptions from a single compositionally stratified magma chamber: an example from Aso volcano, Southwest Japan. J. Volcanol. Geotherm. Res. 167 (1-4), 160-180. https://doi.org/10.1016/j.jvolgeores.2007.05.002.

Kaneko, K., Inoue, K., Koyaguchi, T., Yoshikawa, M., Shibata, T., Takahashi, T., Furukawa, K. 2015. Magma plumbing system of the Aso-3 large pyroclastic eruption cycle at Aso volcano, Southwest Japan: petrological constraint on the formation of a compositionally stratified magma chamber. J. Volcanol. Geotherm. Res. 303, 41-58. https://doi. org/10.1016/j.jvolgeores.2015.07.016.

Kaneshima, S., Kawakatsu, H., Matsubayashi, H., Sudo, Y., Tsutsui, T., Ohminato, T., et al. 1996. Mechanism of phreatic eruptions at Aso volcano inferred from near-field broadband seismic observations. Science 273 (5275), 643-645. https://doi.org/ 10.1126/science.273.5275.643.

Kawakatsu, H., Yamamoto, M., 2007. Volcano seismology. Treatise on Geophysics, 1st ed. 4. Elsevier, pp. 389-420.

Kawakatsu, H., Yamamoto, M., 2015. Volcano seismology. Treatise on Geophysics, 2nd ed. 4. Elsevier, pp. 389-419. https://doi.org/10.1016/B978-0-444-53802-4.00081-6.

Kawakatsu, H., Ohminato, T., Ito, H., 1994. 10s-period volcanic tremors observed over a wide area in southwestern Japan. Geophys. Res. Lett. 21 (18), 1963-1966. https:// doi.org/10.1029/94GL01683.

Kawakatsu, H., Kaneshima, S., Matsubayashi, H., Ohminato, T., Sudo, Y., Tsutsui, T., et al., 2000. Aso 94: Aso seismic observation with broadband instruments. J. Volcanol. Geotherm. Res. 101 (1-2), 129-154. https://doi.org/10.1016/S0377-0273(00) 00166-9.

Kazahaya, R., Mori, T., Takeo, M., Ohminato, T., Urabe, T., Maeda, Y., 2011. Relation between single very-long-period pulses and volcanic gas emissions at Mt. Asama Japan: relation between VLP and gas. Geophys. Res. Lett. 38 (11), L11307. https:// doi.org/10.1029/2011GL047555.

Kedar, S., Sturtevant, B., Kanamori, H., 1996. The origin of harmonic tremor at Old Faithful geyser. Nature 379 (6567), 708-711. https://doi.org/10.1038/379708a0.

Kikuchi, S., 1974. On the Long-period Volcanic Micro-tremors Observed at Mt. Aso. 17. Bulletin of the Disaster Prevention Research Institute, Kyoto Univeristy B, pp. 1-8.

Kilburn, C.R.J., 2003. Multiscale fracturing as a key to forecasting volcanic eruptions. J. Volcanol. Geotherm. Res. 125 (3-4), 271-289. https://doi.org/10.1016/S03770273(03)00117-3.

Kilburn, C.R.J., 2018. Forecasting volcanic eruptions: beyond the failure forecast method. Front. Earth Sci. 6, 133. https://doi.org/10.3389/feart.2018.00133.

Kobayashi, T., Ohminato, T., Ida, Y., Fujita, E., 2009. Very long period seismic signals observed before the caldera formation with the 2000 Miyake-jima volcanic activity Japan. J. Geophys. Res. 114 (B2), B02211. https://doi.org/10.1029/2007JB005557.

Kumagai, H., 2001. Very-long-period seismic signals and caldera formation at Miyake Island, Japan. Science 293 (5530), 687-690. https://doi.org/10.1126/science.1062136.

Kumagai, H., 2003. Magmatic dike resonances inferred from very-long-period seismic signals. Science 299 (5615), 2058-2061. https://doi.org/10.1126/science.1081195.

Kumagai, H., 2009. Source quantification of volcano seismic signals. Encyclopedia of Complexity and Systems Science. Springer-Verlag, New York, pp. 9899-9932.

Kumagai, H., Chouet, B.A., 2000. Acoustic properties of a crack containing magmatic or hydrothermal fluids. Journal of Geophysical Research: Solid Earth 105 (B11) 25493-25512. https://doi.org/10.1029/2000JB900273.

Kumagai, H., Chouet, B.A., 2001. The dependence of acoustic properties of a crack on the resonance mode and geometry. Geophys. Res. Lett. 28 (17), 3325-3328. https://doi. org/10.1029/2001GL013025. 
Kumagai, H., Yepes, H., Vaca, M., Caceres, V., Naga, T., Yokoe, K., et al., 2007. Enhancing volcano-monitoring capabilities in Ecuador. Eos, Transactions American Geophysical Union 88 (23), 245-246. https://doi.org/10.1029/2007EO230001.

Kushnir, A.R.L., Martel, C., Champallier, R., Wadsworth, F.B., 2017. Permeability evolution in variably glassy basaltic andesites measured under magmatic conditions: in situ permeability of volcanic rocks. Geophys. Res. Lett. 44 (20), 271. https://doi.org/ 10.1002/2017GL074042 10, 262-10.

Lane, S.J., James, M.R., 2009. Explosive volcanic eruptions: experimental insights. Encyclopedia of Complexity and Systems Science. Springer-Verlag, New York, pp. 9784-9830.

Lavallée, Y., Meredith, P.G., Dingwell, D.B., Hess, K.-U., Wassermann, J., Cordonnier, B., et al., 2008. Seismogenic lavas and explosive eruption forecasting. Nature 453 (7194), 507-510. https://doi.org/10.1038/nature06980.

Lavallée, Y., Benson, P.M., Heap, M.J., Hess, K.-U., Flaws, A., Schillinger, B., et al., 2013. Reconstructing magma failure and the degassing network of dome-building eruptions. Geology 41 (4), 515-518. https://doi.org/10.1130/G33948.1.

Lees, J.M., 2007. Seismic tomography of magmatic systems. J. Volcanol. Geotherm. Res. 167 (1-4), 37-56. https://doi.org/10.1016/j.jvolgeores.2007.06.008.

Legrand, D., Kaneshima, S., Kawakatsu, H., 2000. Moment tensor analysis of near-field broadband waveforms observed at Aso volcano, Japan. J. Volcanol. Geotherm. Res. 101 (1-2), 155-169. https://doi.org/10.1016/S0377-0273(00)00167-0.

Lim, H., Kim, Y., Song, T.R.A., Shen, X., 2018. Measurement of seismometer orientation using the tangential P-wave receiver function based on harmonic decomposition. Geophys. J. Int. 212 (3), 1747-1765. https://doi.org/10.1093/gji/ggx515.

Lyons, J.J., Waite, G.P., 2011. Dynamics of explosive volcanism at Fuego volcano imaged with very long period seismicity. J. Geophys. Res. 116 (B9), B09303. https://doi.org/ 10.1029/2011JB008521.

Maeda, Y., Takeo, M., 2011. Very-long-period pulses at Asama volcano, central Japan, inferred from dense seismic observations. Geophys. J. Int. 185 (1), 265-282. https:// doi.org/10.1111/j.1365-246X.2011.04938.X.

Maeda, Y., Kato, A., Terakawa, T., Yamanaka, Y., Horikawa, S., Matsuhiro, K., Okuda, T. 2015. Source mechanism of a VLP event immediately before the 2014 eruption of Mt. Ontake, Japan. Earth, Planets and Space 67 (1), 187. https://doi.org/10.1186/ s40623-015-0358-0.

Magee, C., Stevenson, C.T.E., Ebmeier, S.K., Keir, D., Hammond, J.O.S., Gottsmann, J.H., et al , 2018. Magma plumbing systems: a geophysical perspective. J. Petrol. 59 (6) 1217-1251. https://doi.org/10.1093/petrology/egy064.

Mallat, S.G., 2009. A Wavelet Tour of Signal Processing: The Sparse Way. 3rd ed. Elsevier/ Academic Press, Amsterdam; Boston.

McNutt, S.R. 1996. Seismic monitoring and eruption forecasting of volcanoes: a review of the state-of-the-art and case histories. In: Scarpa, R, Tilling, R.I. (Eds.), Monitoring and Mitigation of Volcano Hazards. Springer Berlin Heidelberg, Berlin, Heidelberg, pp. 99-146. https://doi.org/10.1007/978-3-642-80087-0_3.

McNutt, S.R., 2005. Volcanic seismology. Annu. Rev. Earth Planet. Sci. 33 (1), 461-491. https://doi.org/10.1146/annurev.earth.33.092203.122459.

Melnik, O., Sparks, R.S.J., 1999. Nonlinear dynamics of lava dome extrusion. Nature 402 (6757), 37-41. https://doi.org/10.1038/46950.

Minakami, T., 1974. Seismology of volcanoes in Japan. Developments in Solid Earth Geophysics. 6. Elsevier, pp. 1-27. https://doi.org/10.1016/B978-0-444-41141-9.50007-3.

Minami, T., Utsugi, M., Utada, H., Kagiyama, T., Inoue, H., 2018. Temporal variation in the resistivity structure of the first Nakadake crater, Aso volcano, Japan, during the mag matic eruptions from November 2014 to May 2015, as inferred by the ACTIVE electromagnetic monitoring system. Earth, Planets and Space 70 (1), 138. https://doi. org/10.1186/s40623-018-0909-2.

Miyabuchi, Y., 2009. A 90, 000-year tephrostratigraphic framework of Aso Volcano, Japan. Sediment. Geol. 220 (3-4), 169-189. https://doi.org/10.1016/j.sedgeo.2009.04.018.

Miyabuchi, Y., 2011. Post-caldera explosive activity inferred from improved 67-30ka tephrostratigraphy at Aso Volcano, Japan. J. Volcanol. Geotherm. Res. 205 (3-4), 94-113. https://doi.org/10.1016/j.jvolgeores.2011.05.004

Miyabuchi, Y., Hara, C., 2019. Temporal variations in discharge rate and component characteristics of tephra-fall deposits during the 2014-2015 eruption of Nakadake firs rater, Aso Volcano, Japan. Earth, Planets and Space 71 (1), 44. https://doi.org/ 10.1186/s40623-019-1018-6.

Miyabuchi, Y., Watanabe, K., Egawa, Y., 2006. Bomb-rich basaltic pyroclastic flow deposit from Nakadake, Aso Volcano, southwestern Japan. J. Volcanol. Geotherm. Res. 155 (1-2), 90-103. https://doi.org/10.1016/j.jvolgeores.2006.02.007.

Miyabuchi, Y., Iizuka, Y., Hara, C., Yokoo, A., Ohkura, T., 2018. The September 14, 2015 phreatomagmatic eruption of Nakadake first crater Aso Volcano, Japan: eruption sequence inferred from ballistic, pyroclastic density current and fallout deposits. J. Volcanol. Geotherm. Res. 351, 41-56. https://doi.org/10.1016/j. jvolgeores.2017.12.009.

Miyoshi, M., Sumino, H., Miyabuchi, Y., Shinmura, T., Mori, Y., Hasenaka, T., et al., 2012. K$\mathrm{Ar}$ ages determined for post-caldera volcanic products from Aso volcano, central Kyushu, Japan. J. Volcanol. Geotherm. Res. 229-230, 64-73. https://doi.org/10.1016/j. jvolgeores.2012.04.003.

Miyoshi, M., Shinmura, T., Sumino, H., Sano, T., Miyabuchi, Y., Mori, Y., et al., 2013. Lateral magma intrusion from a caldera-forming magma chamber: constraints from geochronology and geochemistry of volcanic products from lateral cones around the Aso caldera, SW Japan. Chem. Geol. 352, 202-210. https://doi.org/10.1016/j. chemgeo.2013.06.003.

Mordensky, S.P., Heap, M.J., Kennedy, B.M., Gilg, H.A., Villeneuve, M.C., Farquharson, J.I. Gravley, D.M., 2019. Influence of alteration on the mechanical behaviour and failure mode of andesite: implications for shallow seismicity and volcano monitoring. Bull. Volcanol. 81 (8), 44. https://doi.org/10.1007/s00445-019-1306-9.
Mori, T., Sudo, Y., Tsutsui, T., Yoshikawa, S., 2008. Characteristics of isolated hybrid tremor (HBT) during a calm activity period at Aso Volcano. Bull. Volcanol. 70 (9), 1031-1042. https://doi.org/10.1007/s00445-007-0185-7.

Nadeau, P.A., Palma, J.L., Waite, G.P., 2011. Linking volcanic tremor, degassing, and eruption dynamics via $\mathrm{SO}_{2}$ imaging: linking volcanic tremor and degassing. Geophys. Res. Lett. 38 (1). https://doi.org/10.1029/2010GL045820 n/a-n/a.

Namiki, A., Tanaka, Y., Yokoyama, T., 2018. Physical characteristics of scoriae and ash from 2014-2015 eruption of Aso Volcano, Japan. Earth, Planets and Space 70 (1), 147. https://doi.org/10.1186/s40623-018-0914-5.

Nara, Y., Meredith, P.G., Yoneda, T., Kaneko, K., 2011. Influence of macro-fractures and micro-fractures on permeability and elastic wave velocities in basalt at elevated pressure. Tectonophysics 503 (1-2), 52-59. https://doi.org/10.1016/j.tecto.2010.09.027.

Neuberg, J.W., 2011. Earthquakes, volcanogenic. Encyclopedia of Solid Earth Geophysics. Springer Netherlands, Dordrecht, pp. 261-269. https://doi.org/10.1007/978-90-4818702-7.

Neuberg, J., Luckett, R., Ripepe, M., Braun, T., 1994. Highlights from a seismic broadband array on Stromboli Volcano. Geophys. Res. Lett. 21 (9), 749-752. https://doi.org/ 10.1029/94GL00377.

Neuberg, J.W., Tuffen, H., Collier, L., Green, D., Powell, T., Dingwell, D., 2006. The trigger mechanism of low-frequency earthquakes on Montserrat. J. Volcanol. Geotherm. Res. 153 (1-2), 37-50. https://doi.org/10.1016/j.jvolgeores.2005.08.008.

Nishimura, T., Iguchi, M., 2011. Volcanic Earthquakes and Tremor in Japan. Kyoto University Press, Kyoto.

Nishimura, T., Nakamichi, H., Tanaka, S., Sato, M., Kobayashi, T., Ueki, S., et al., 2000. Source process of very long period seismic events associated with the 1998 activity of Iwate Volcano, northeastern Japan. Journal of Geophysical Research: Solid Earth 105 (B8), 19135-19147. https://doi.org/10.1029/2000JB900155.

Nishimura, T. Ueki, S., Yamawaki, T., Tanaka, S., Hashino, H., Sato, M., et al., 2003. Broadband seismic signals associated with the 2000 volcanic unrest of Mount Bandai, northeastern Japan. J. Volcanol. Geotherm. Res. 119 (1-4), 51-59. https://doi.org/ 10.1016/S0377-0273(02)00305-0.

Ohminato, T., Ereditato, D., 1997. Broadband seismic observations at Satsuma-Iwojima volcano, Japan. Geophys. Res. Lett. 24 (22), 2845-2848. https://doi.org/10.1029/ 97GL02903.

Ohminato, T., Takeo, M., Kumagai, H., Yamashina, T., Oikawa, J., Koyama, E., et al., 2006. Vulcanian eruptions with dominant single force components observed during the Asama 2004 volcanic activity in Japan. Earth, Planets and Space 58 (5), 583-593. https://doi.org/10.1186/BF03351955.

Okumura, S., Nakamura, M., Nakano, T., Uesugi, K., Tsuchiyama, A., 2010. Shear deformation experiments on vesicular rhyolite: implications for brittle fracturing, degassing, and compaction of magmas in volcanic conduits. J. Geophys. Res. 115 (B6), B06201. https://doi.org/10.1029/2009JB006904

Okumura, S., Nakamura, M., Uesugi, K., Nakano, T., Fujioka, T., 2013. Coupled effect of magma degassing and rheology on silicic volcanism. Earth Planet. Sci. Lett. 362, 163-170. https://doi.org/10.1016/j.epsl.2012.11.056.

Ono, K., Watanabe, K., Hoshizumi, H., Ikebe, S., 1995. Ash eruption of the Naka-dake crater, Aso volcano, southwestern Japan. J. Volcanol. Geotherm. Res. 66 (1-4), 137-148. https://doi.org/10.1016/0377-0273(94)00061-K.

Paterson, M.S., Wong, T., 2005. Experimental Rock Deformation-The Brittle Field. Springer Science \& Business Media.

Pinel, V., Poland, M.P., Hooper, A., 2014. Volcanology: lessons learned from synthetic aperture radar imagery. J. Volcanol. Geotherm. Res. 289, 81-113.

Plail, M., Edmonds, M., Humphreys, M.C.S., Barclay, J., Herd, R.A., 2014. Geochemical evidence for relict degassing pathways preserved in andesite. Earth Planet. Sci. Lett. 386, 21-33. https://doi.org/10.1016/j.epsl.2013.10.044.

Plank, T., Kelley, K.A., Zimmer, M.M., Hauri, E.H., Wallace, P.J., 2013. Why do mafic arc magmas contain $\sim 4$ wt\% water on average? Earth Planet. Sci. Lett. 364, 168-179. https://doi.org/10.1016/j.epsl.2012.11.044.

Poland, M., Hamburger, M., Newman, A., 2006. The changing shapes of active volcanoes: history, evolution, and future challenges for volcano geodesy. J. Volcanol. Geotherm. Res. 150, 1-3, 1-13.

Roman, D.C., Cashman, K.V., 2006. The origin of volcano-tectonic earthquake swarms. Geology 34 (6), 457. https://doi.org/10.1130/G22269.1.

Rowe, C.A., Aster, R.C., Kyle, P.R., Schlue, J.W., Dibble, R.R., 1998. Broadband recording of Strombolian explosions and associated very-long-period seismic signals on Mount Erebus Volcano, Ross Island, Antarctica. Geophys. Res. Lett. 25 (13), 2297-2300. https://doi.org/10.1029/98GL01622.

Saito, G., Ishizuka, O., Ishizuka, Y., Hoshizumi, H., Miyagi, I., 2018. Petrological characteristics and volatile content of magma of the 1979, 1989, and 2014 eruptions of Nakadake, Aso volcano, Japan. Earth, Planets and Space 70 (1), 197. https://doi.org/ 10.1186/s40623-018-0970-x

Sandanbata, O., Obara, K., Maeda, T., Takagi, R, Satake, K., 2015. Sudden changes in the amplitude-frequency distribution of long-period tremors at Aso volcano, southwest Japan: sudden changes in long-period volcanic tremors. Geophys. Res. Lett. 42 (23), 10,256-10,262. https://doi.org/10.1002/2015GL066443.

Sassa, K., 1935. Geophysical studies on the volcano Aso. (Part 1: volcanic micro-tremors and eruptive-earthquakes). Memoirs of the College of Science, Kyoto Imperial University. Series A 255-293.

Sato, E Fukui, K., Shimbori, T. 2018. Aso volcano eruption on October 8,2016 observed by weather radars. Earth, Planets and Space 70 (1), 105. https://doi.org/10.1186/ s40623-018-0879-4.

Segall, P., 2013. Volcano deformation and eruption forecasting. Geol. Soc. Lond., Spec. Publ. 380 (1), 85-106. https://doi.org/10.1144/SP380.4.

Shapiro, N., Droznin, D., Droznina, S.Y., Senyukov, S., Gusev, A., Gordeev, E., 2017. Deep and shallow long-period volcanic seismicity linked by fluid-pressure transfer. Nat. Geosci. 10 (6), 442-445. 
Shelly, D.R., Beroza, G.C., Ide, S., 2007. Non-volcanic tremor and low-frequency earthquake swarms. Nature 446 (7133), 305-307. https://doi.org/10.1038/nature05666.

Shinohara, H., 2013. Volatile flux from subduction zone volcanoes: insights from a detailed evaluation of the fluxes from volcanoes in Japan. J. Volcanol. Geotherm. Res. 268, 46-63. https://doi.org/10.1016/j.jvolgeores.2013.10.007.

Sparks, R.S.J., 2003. Dynamics of magma degassing. Geol. Soc. Lond., Spec. Publ. 213 (1), 5-22. https://doi.org/10.1144/GSL.SP.2003.213.01.02.

Sparks, R.S.J., Cashman, K.V., 2017. Dynamic magma systems: implications for forecasting volcanic activity. Elements 13 (1), 35-40. https://doi.org/10.2113/ gselements.13.1.35.

Sudo, Y., Kong, L., 2001. Three-dimensional seismic velocity structure beneath Aso volcano, Kyushu, Japan. Bull. Volcanol. 63 (5), 326-344. https://doi.org/10.1007/ s004450100145.

Sudo, Y., Tsutsui, T., Nakaboh, M., 2006. Ground deformation and magma reservoir at Aso volcano: location of deflation source derived from long-term geodetic surveys (in Japanese). Bulletin of the Volcanological Society of Japan 51, 291-309.

Takagi, N., Kaneshima, S., Kawakatsu, H., Yamamoto, M., Sudo, Y., Ohkura, T., et al., 2006. Apparent migration of tremor source synchronized with the change in the tremor amplitude observed at Aso volcano, Japan. J. Volcanol. Geotherm. Res. 154 (3-4), 181-200. https://doi.org/10.1016/j.jvolgeores.2006.02.001.

Takagi, N., Kaneshima, S., Ohkura, T., Yamamoto, M., Kawakastu, H., 2009. Long-term variation of the shallow tremor sources at Aso Volcano from 1999 to 2003. J. Volcanol. Geotherm. Res. 184 (3-4), 333-346. https://doi.org/10.1016/j. jvolgeores.2009.04.013.

Tanada, T., Ueda, H., Nagai, M., Ukawa, M., National Research Institute for Earth Science and Disaster Resilience (NIED) Tennodai, Tsukuba, Ibaraki 305-0006, Japan, \& Department of Earth and Environmental Sciences, College of Humanities and Sciences, Nihon University, Tokyo, Japan, 2017. NIED's V-net, the fundamental volcano observation network in Japan. Journal of Disaster Research 12 (5), 926-931. https://doi. org/10.20965/jdr.2017.p0926.

Tanaka, Y., 1993. Eruption mechanism as inferred from geomagnetic changes with special attention to the 1989-1990 activity of Aso volcano. J. Volcanol. Geotherm. Res. 56 (3), 319-338. https://doi.org/10.1016/0377-0273(93)90024-L

Terada, A., Hashimoto, T., Kagiyama, T., 2012. A water flow model of the active crater lake at Aso volcano, Japan: fluctuations of magmatic gas and groundwater fluxes from the underlying hydrothermal system. Bull. Volcanol. 74 (3), 641-655. https://doi.org/ 10.1007/s00445-011-0550-4.

Turin, G., 1960. An introduction to matched filters. IEEE Trans. Inf. Theory 6 (3), 311-329. https://doi.org/10.1109/TIT.1960.1057571.

Uhira, K., Yamasato, H., Takeo, M., 1994. Source mechanism of seismic waves excited by pyroclastic flows observed at Unzen volcano, Japan. Journal of Geophysical Research: Solid Earth 99 (B9), 17757-17773. https://doi.org/10.1029/94JB00110.

Unglert, K., Savage, M.K., Fournier, N., Ohkura, T., Abe, Y., 2011. Shear wave splitting, $v_{P} / v_{S}$ and GPS during a time of enhanced activity at Aso caldera, Kyushu: shear wave splitting and GPS at Aso. Journal of Geophysical Research: Solid Earth 116 (B11), B11203. https://doi.org/10.1029/2011JB008520.

Vinciguerra, S., Trovato, C., Meredith, P.G., Benson, P.M., 2005. Relating seismic velocities, thermal cracking and permeability in Mt. Etna and Iceland basalts. Int. J. Rock Mech. Min. Sci. 42 (7-8), 900-910. https://doi.org/10.1016/j.jjrmms.2005.05.022.
Voight, B., 1988. A method for prediction of volcanic eruptions. Nature 332 (6160), 125-130. https://doi.org/10.1038/332125a0.

Waite, G.P., 2014. Very-long-period seismicity at active volcanoes: source mechanisms In: Beer, M., Kougioumtzoglou, I.A., Patelli, E., Au, I.S.-K. (Eds.), Encyclopedia of Earthquake Engineering. Springer Berlin Heidelberg, Berlin, Heidelberg, pp. 1-12. https:// doi.org/10.1007/978-3-642-36197-5_46-1.

Waite, G.P., Chouet, B.A., Dawson, P.B., 2008. Eruption dynamics at Mount St. Helens imaged from broadband seismic waveforms: interaction of the shallow magmatic and hydrothermal systems. J. Geophys. Res. 113 (B2), B02305. https://doi.org/10.1029/ 2007JB005259.

Waite, G.P., Nadeau, P.A., Lyons, J.J., 2013. Variability in eruption style and associated very long period events at Fuego volcano, Guatemala. Journal of Geophysical Research: Solid Earth 118 (4), 1526-1533. https://doi.org/10.1002/jgrb.50075.

Walsh, J.B., 1981. Effect of pore pressure and confining pressure on fracture permeability International Journal of Rock Mechanics and Mining Sciences \& Geomechanics Abstracts 18 (5), 429-435. https://doi.org/10.1016/0148-9062(81)90006-1.

Woods, A.W., Koyaguchi, T., 1994. Transitions between explosive and effusive eruptions of silicic magmas. Nature 370 (6491), 641-644. https://doi.org/10.1038/370641a0.

Yamamoto, M., Kawakatsu, H., Kaneshima, S., Mori, T., Tsutsui, T., Sudo, Y., Morita, Y., 1999. Detection of a crack-like conduit beneath the active crater at Aso volcano Japan. Geophys. Res. Lett. 26 (24), 3677-3680. https://doi.org/10.1029/ 1999 GL005395.

Yamamoto, M., Kawakatsu, H., Yomogida, K., Koyama, J., 2002. Long-period (12 sec) volcanic tremor observed at Usu 2000 eruption: seismological detection of a deep magma plumbing system. Geophysical Research Letters 29 (9). https://doi.org/ 10.1029/2001GL013996 43-1-43-4.

Yokoo, A., Miyabuchi, Y., 2015. Eruption at the Nakadake 1st crater of Aso volcano started in November 2014 (in Japanese). Bulletin of the Volcanological Society of Japan 60 275-278.

Zellmer, G.F., Iizuka, Y., Miyoshi, M., Tamura, Y., Tatsumi, Y., 2012. Lower crustal H2O controls on the formation of adakitic melts. Geology 40 (6), 487-490. https://doi.org/ $10.1130 / \mathrm{G} 32912.1$

Zhu, L., Rivera, L.A., 2002. A note on the dynamic and static displacements from a point source in multilayered media: a note on the dynamic and static displacements from a point source. Geophys. J. Int. 148 (3), 619-627. https://doi.org/10.1046/ j.1365-246X.2002.01610.x.

Zoback, M.D., Byerlee, J., 1975. Permeability and effective stress. AAPG Bull. 59 (1), $154-158$.

Zobin, V.M., 2011. Introduction to Volcanic Seismology. Elsevier Science \& Technology Books, Amsterdam, Nederlands.

Zuccarello, L., Burton, M.R., Saccorotti, G., Bean, C.J., Patanè, D., 2013. The coupling between very long period seismic events, volcanic tremor, and degassing rates a Mount Etna volcano: comparison VLP, tremor, and gas flux at Etna. Journal of Geophysical Research: Solid Earth 118 (9), 4910-4921. https://doi.org/10.1002/ jgrb.50363. 